\title{
OPEN A carotenoid-deficient mutant of the plant-associated microbe Pantoea sp. YR343 displays an altered membrane proteome
}

\begin{abstract}
Sushmitha Vijaya Kumar ${ }^{1}$, Paul E. Abraham², Gregory B. Hurst ${ }^{2}$, Karuna Chourey², Amber N. Bible ${ }^{1}$, Robert L. Hettich², Mitchel J. Doktycz ${ }^{1,4,5}$ \& Jennifer L. Morrell-Falvey ${ }^{1,3,4} \bowtie$

Membrane organization plays an important role in signaling, transport, and defense. In eukaryotes, the stability, organization, and function of membrane proteins are influenced by certain lipids and sterols, such as cholesterol. Bacteria lack cholesterol, but carotenoids and hopanoids are predicted to play a similar role in modulating membrane properties. We have previously shown that the loss of carotenoids in the plant-associated bacteria Pantoea sp. YR343 results in changes to membrane biophysical properties and leads to physiological changes, including increased sensitivity to reactive oxygen species, reduced indole-3-acetic acid secretion, reduced biofilm and pellicle formation, and reduced plant colonization. Here, using whole cell and membrane proteomics, we show that the deletion of carotenoid production in Pantoea sp. YR343 results in altered membrane protein distribution and abundance. Moreover, we observe significant differences in the protein composition of detergent-resistant membrane fractions from wildtype and mutant cells, consistent with the prediction that carotenoids play a role in organizing membrane microdomains. These data provide new insights into the function of carotenoids in bacterial membrane organization and identify cellular functions that are affected by the loss of carotenoids.
\end{abstract}

Biological membranes serve as a central scaffold for cellular machinery that regulate key physiological functions including signaling, defense, metabolism, and molecular transport ${ }^{1,2}$. Indeed, genes encoding membrane proteins account for $20-30 \%$ of the entire genetic complement of a bacterial cell ${ }^{3,4}$. These membrane proteins are important for processes such as cell motility, chemotaxis, cyclic dimeric guanosine monophosphate (c di-GMP) signaling, virulence, multidrug efflux, and outer membrane biogenesis ${ }^{5-7}$. Bacterial outer membrane proteins are also directly involved in bacterial acclimatization by monitoring and responding to environmental cues.

Apart from proteins and lipids, some membranes contain carotenoids. These compounds have been implicated in photoprotection, imparting coloration to plants, animals and bacteria, and used as a chromophore in photosynthesis $^{8-11}$. In the photosynthetic apparatus of plants, algae, and bacteria, carotenoids are found in the light-harvesting pigment-protein complexes ${ }^{12}$. In bacterial membranes, carotenoids have been shown to reinforce membranes and modulate membrane thickness and fluidity ${ }^{13-17}$. These properties are essential for many key molecular processes, such as signal transduction, that involve the movement of proteins in the membrane. Therefore, changes in the structure and dynamics of a membrane due to carotenoids can further affect cellular events occurring at the membrane.

The existence of membrane microdomains has traditionally been associated with eukaryotic membranes, but recent studies have shown that some bacteria, such as Bacillus subtilis, can form functional membrane microdomains ${ }^{18}$. The formation of these microdomains in prokaryotes is thought to involve sterol analogs, such as hopanoids and carotenoids ${ }^{18,19}$. Eukaryotic membrane microdomains, sometimes called lipid rafts, are characterized by the presence of cholesterol and flotillin ${ }^{18-20}$. The activity of flotillin in eukaryotes is critical for the functioning of lipid raft-associated cellular processes, such as membrane trafficking and cell polarization ${ }^{21-23}$. Homologs of flotillin have also been identified in prokaryotes ${ }^{24-26}$ and these prokaryotic flotillins also appear

${ }^{1}$ UT-ORNL Graduate School of Genome Science and Technology, University of Tennessee, Knoxville, TN, USA. ${ }^{2}$ Chemical Sciences Division, Oak Ridge National Laboratory, Oak Ridge, TN, USA. ${ }^{3}$ Department of Biochemistry and Cellular and Molecular Biology, University of Tennessee, Knoxville, TN, USA. ${ }^{4}$ Biosciences Division, Oak Ridge National Laboratory, Oak Ridge, TN, USA. ${ }^{5}$ Center for Nanophase Materials Sciences, Oak Ridge National Laboratory, Oak Ridge, TN, USA. ${ }^{\circledR}$ email: morrelljl1@ornl.gov 
to organize the membrane into domains, enabling protein interactions and oligomerization ${ }^{19,25,27}$. This lateral membrane organization and sub-compartmentalization is critical for efficient membrane function ${ }^{28}$.

We have shown previously that the loss of carotenoids in the plant-associated bacteria Pantoea sp. YR343 results in cells that are more susceptible to oxidative damage, but also display defects in plant root colonization, biofilm formation, and in indole-3-acetic acid secretion ${ }^{29}$. Lipid profiling of this carotenoid-deficient mutant (generated by deleting the $c r t B$ gene encoding phytoene synthase) demonstrated that the mutant strain displays an increase in phosphatidylethanolamine and unsaturated fatty acids when compared to wildtype cells ${ }^{17}$. Moreover, these differences in lipid profiles also translate to differences in membrane fluidity between the wildtype and the $\Delta c r t B$ mutant ${ }^{17}$. From these studies, it is evident that the loss of carotenoids from the membrane leads to changes in membrane properties and organization, thereby influencing cellular functions. In this paper, we examine the proteomic profile of $\Delta c r t B$ mutant cells compared to wildtype to better understand the role of carotenoids in membrane organization. To this end, we compare proteomic profiles of whole cells, membrane fractions, and the distribution of membrane proteins in detergent-resistant membrane (DRM) and detergentsensitive membrane (DSM) fractions.

\section{Results and discussion}

Identification and quantification of protein abundances in Pantoea sp. YR343 and $\Delta c r t B$ whole cells, membrane pellet, detergent resistant membranes (DRM) and detergent sensitive membrane (DSM) samples. Because we observed changes in the membrane lipid profiles and membrane fluidity in Pantoea sp. YR343 cells lacking carotenoids ${ }^{17}$, we wanted to determine how the loss of carotenoids affected the membrane proteome. To this end, whole cell, membrane pellet (MP), DRM, and DSM samples from Pantoea sp. YR343 and $\Delta c r t B$ strains harvested during stationary phase were used for proteome characterization. Equal amounts of protein from each fraction were analyzed by proteomics, although we measured reduced protein concentrations from the mutant membrane, DRM, and DSM fractions (see Methods). Overall, an average of 2,153 and 2046 proteins were identified for wildtype and $\Delta c r t B$ whole cells, with an average proteome coverage of $44 \%$ and $42 \%$ respectively. For the membrane fractions investigated, 1,363 (28\%) and 1,270 (26\%) proteins were identified for wildtype and $\Delta c r t B$ MP samples, $1,311(27 \%)$ and 1,196 (24\%) proteins were identified for the wildtype and $\Delta c r t B$ DRM samples and $645(13 \%)$ and $653(13 \%)$ proteins were identified for wildtype and $\Delta c r t B$ DSM samples (Fig. 1a). A Venn diagram comparing the proteins identified in four different conditions is shown in Fig. 1b, illustrating the intersections between proteomes. A total of 592 and 545 proteins were found in all four wildtype and $\triangle c r t B$ mutant samples, respectively.

Principle component analysis (PCA) (Fig. 1c) of the proteome data indicated distinct groupings for proteins isolated from the whole cell, membrane pellet, and DSM fractions in each of the wildtype and $\Delta c r t B$ biological replicates $(n=3)$, indicating reproducibility between replicates as well as similarity between the two strains (wildtype and $\Delta c r t B$ mutant). In contrast, a scattered distribution was observed for the wildtype and $\Delta c r t B$ DRM samples (Fig. 1c). Major variance was observed in PC1 (discrete grouping of samples) with DSM samples and in PC2 (major variance) across the remaining factors. Sterols are vital components in the formation of membrane microdomains ${ }^{19}$ and proteins that localize to lipid rafts or microdomains are typically found in the detergent-resistant membrane fractions ${ }^{18,30}$. Thus, the absence of carotenoids may affect the formation, stability, or recruitment of proteins to microdomains, resulting in the observed differences between the wildtype and $\triangle c r t B$ mutant DRM fractions. Proper functioning of proteins is regulated by membrane bilayer properties such as lipid curvature, bilayer thickness, and elastic properties provided by sterols ${ }^{31}$. Molecular dynamics simulations of the carotenoid zeaxanthin with 1,2-dimyristoyl-sn-glycero-3-phosphocholine (DMPC) bilayers have shown that carotenoids influence the physical properties of bilayers ${ }^{32}$. Unlike cholesterol which can only span one leaflet of the lipid bilayer, a C40 carotenoid can span both leaflets ${ }^{14}$. A recent study has shown that zeaxanthin can trigger the bilayer to become thinner through the process of interdigitation or compression ${ }^{16}$. It has been well established that bilayer thickness, which is modulated by phospholipid chain composition and sterol content, is a critical factor for the proper insertion and function of membrane proteins ${ }^{33,34}$. Thus, the differences in protein composition and abundance detected in the $\Delta c r t B$ mutant could be due to changes in membrane thickness as a result of the loss of carotenoids.

To test for the enrichment of membrane proteins in each fraction, we used TMHMM software, a membrane protein topology prediction method, in order to identify proteins containing at least one transmembrane helix, with a maximum number of transmembrane helices detected at 17 . Approximately $24 \%$ of the proteome of Pantoea sp. YR343 consists of proteins with at least one transmembrane helix. As shown in Fig. 2, the largest enrichment of proteins with transmembrane helices for this study was found in the wildtype and $\Delta c r t B$-DSM samples. In general, the proportion of membrane proteins to other cellular proteins is low and the limitations of solubility and separation may limit their detection and identification ${ }^{35}$. While the proportion of proteins with transmembrane helices was similar between the wildtype and mutant in the whole cell, membrane fraction, and DSM fractions, we observed that the $\triangle c r t B$ DRM fraction had fewer proteins with transmembrane helices compared to the wildtype DRM fraction (Fig. 2). This result is consistent with the idea that changes in membrane thickness or microdomain organization due to loss of carotenoids influences protein recruitment or localization, as mentioned previously. It should be noted that this analysis cannot identify membrane-associated proteins that might also be influenced by the loss of carotenoids. In addition, membrane microdomains are known to be transient structures and their identification depends on the state of cellular activity ${ }^{36}$. For this reason, it is possible that the observed proteome differences between wildtype and mutant cells are due to physiological differences between the cultures, even though care was taken to harvest both cultures during stationary phase.

Next, hierarchical clustering was used to assess the differences in abundance of all proteins identified in the four fractions for wildtype and $\Delta c r t B$ cells (Fig. 3). From this analysis, we found that each sample fraction (whole 

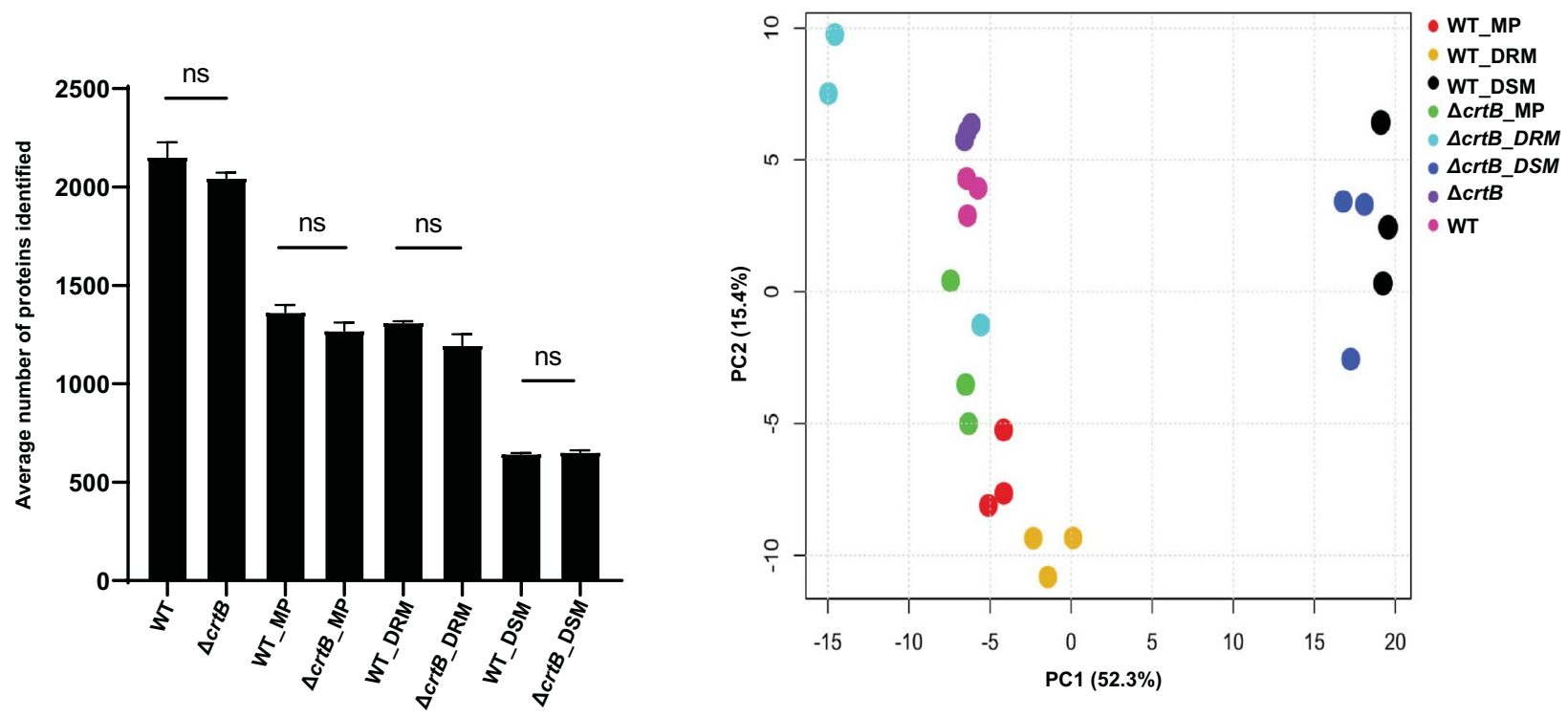

b
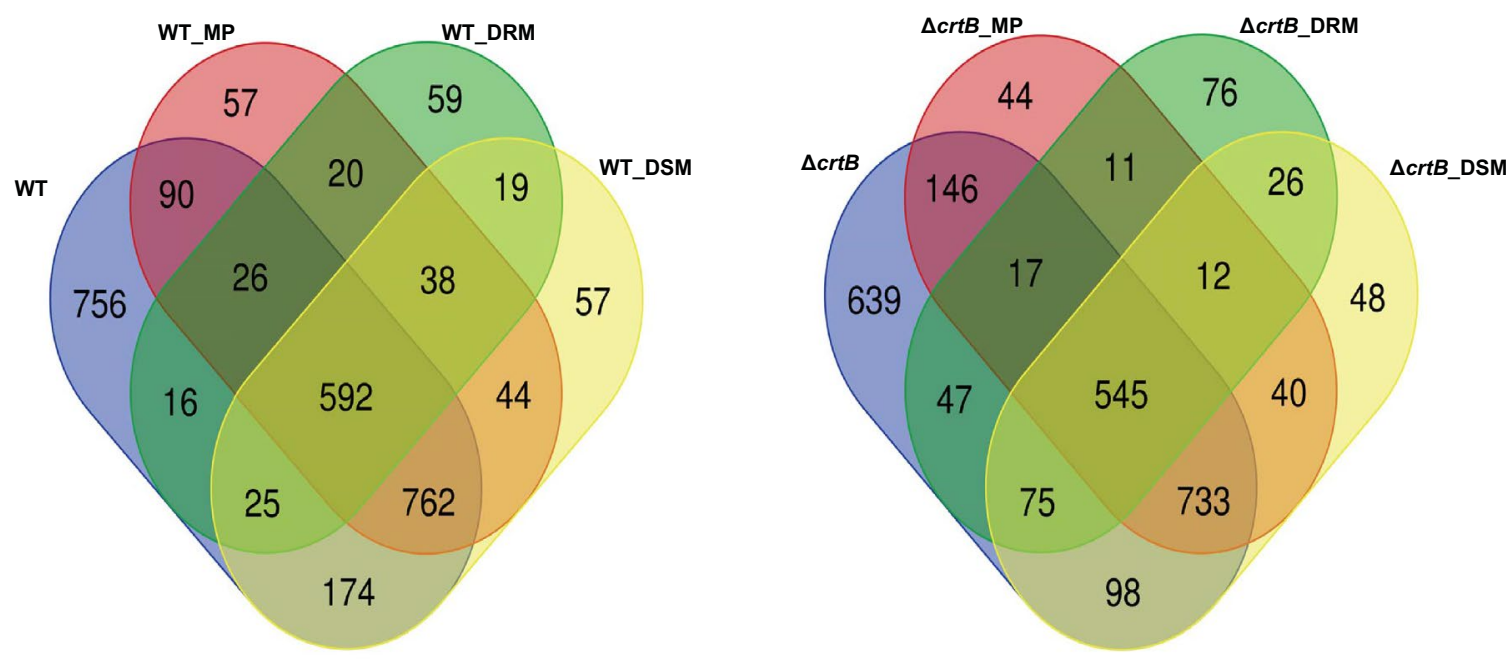

Figure 1. Identification and analysis of the proteins identified in whole cell, membrane pellet, DRM and DSM fractions of Pantoea sp. YR343 and $\Delta c r t B$ mutant cells. (a) Histogram representing the number of proteins (averaged from 3 biological replicates) identified from whole cell, membrane fraction (MP), detergent resistant membrane fraction (DRM) and detergent sensitive membrane fractions (DSM) for wild type and the $\Delta \operatorname{crt} B$ mutant using proteomics. Statistical significance was calculated by One-way ANOVA. ns non-significant. (b) Venn diagrams comparing the number of identified proteins in common between different samples (whole cell, MP, DRM and DSM). Each ellipse from WT or the mutant represent whole cell, MP, DRM or DSM samples, with the number of common proteins between samples shown in the overlapping regions. The number in the non-overlapping region represents unique proteins for each sample. (c) Comparison of samples using principle component analysis (PCA) based on normalized abundance. The plot illustrates discrete grouping of biological replicates with a major variance observed in PC1 for the DSM samples and in PC2 across the remaining factors.

cell, membrane, DRM, or DSM) clustered together. A Student's t-test (paired t-test) was performed and a $p$ value cutoff of $\leq 0.05$ and a fold change (FC) of $\geq 2$ was used to identify proteins with relative abundances that significantly differed between the wildtype and $\Delta c r t B$ samples. In total, 240, 134, 297 and 71 proteins were differentially abundant between wildtype and $\Delta c r t B$ cells for the whole cell, MP, DRM and DSM fractions, respectively (Fig. 4). Out of these, 188 (in whole cell), 111 (in MP), 211 (in DRM) and 44 (in DSM), were significantly less abundant in the $\Delta c r t B$ mutant in comparison to the wildtype, In total, 21 proteins were found to be differentially abundant across all four fractions in both wild type and $\Delta c r t B$ cells. The observed phenotypes found in the $\Delta c r t B$ mutant may be a result of the changes in abundance or distribution of these identified proteins. 


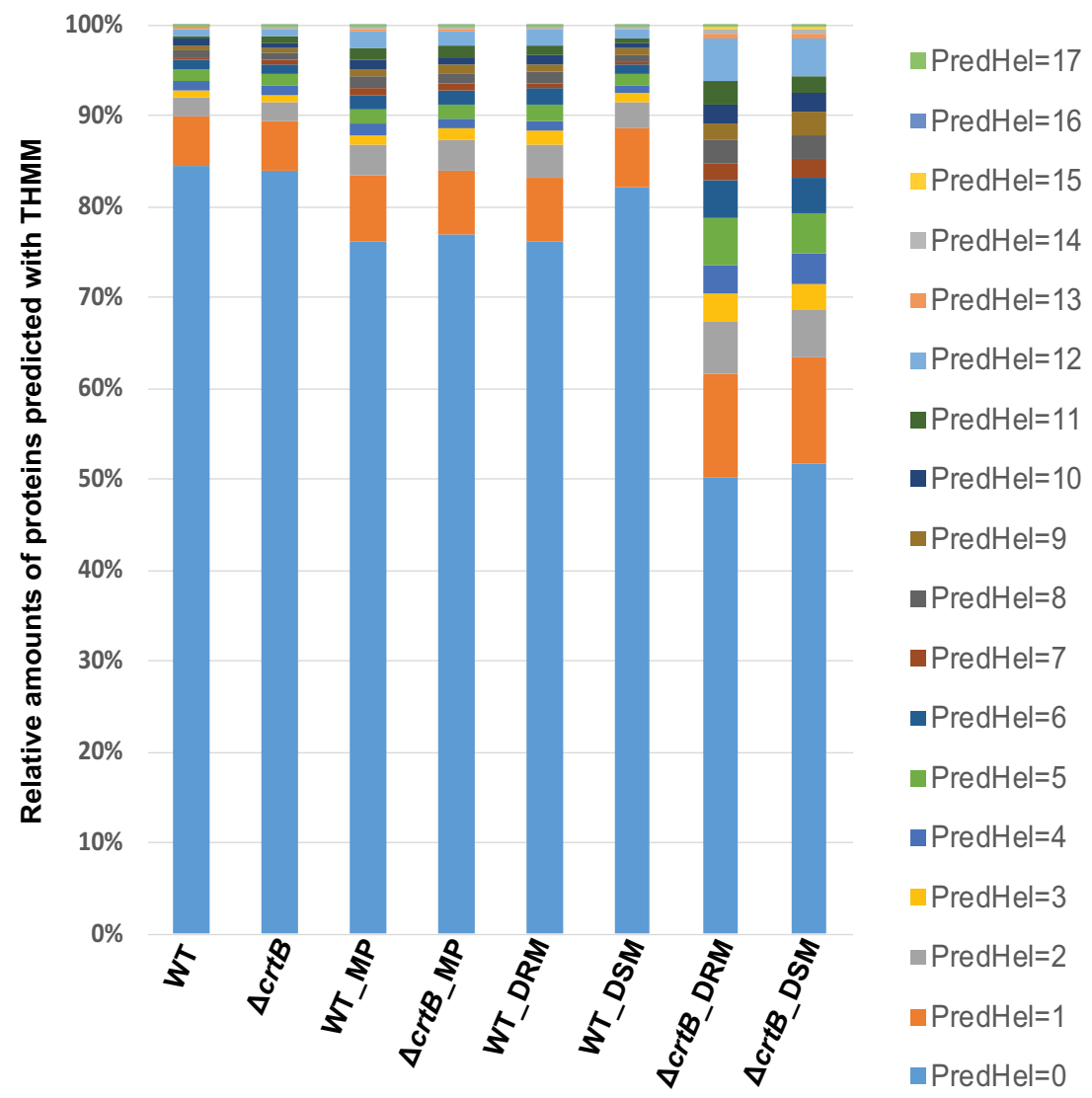

Figure 2. Histogram representing the percentage of proteins with predicted transmembrane helix domains (TMHMM) for each sample. Proteins with predicted transmembrane helices were identified using TMHMM software. The membrane fraction samples contain higher relative amounts of proteins with predicted TMHMM domains, with the DSM fraction having the largest enrichment.

Cluster of orthologous groups (COG) analysis. To identify biological processes related to the differentially abundant proteins, functional classification of significant proteins was carried out using the COG database $^{37}$. Significant proteins were grouped into 21 functional classes according to COG classification. Proteins belonging to transcription $(\mathrm{K})$ and carbohydrate transport and metabolism $(\mathrm{G})$ categories were abundant in whole cell samples, whereas cell wall/membrane/envelope biogenesis $(\mathrm{M})$ proteins were abundant in membrane pellet, DRM, and DSM fractions (Fig. 5).

Gene ontology (GO) enrichment analysis. To gain a deeper understanding of overall changes in protein abundance and distribution between the wildtype and $\Delta c r t B$ mutant, functional in silico classification of proteins was achieved via GO analysis using the BLAST2GO tool ${ }^{38}$. All of the proteins that were differentially abundant ( $p$ value $\leq 0.05$ and a FC $\geq 2$ ) based on the proteomic analyses were organized by GO terms to determine which biological processes were affected by the loss of carotenoids (Table 1).

In the whole cell pairwise comparisons, proteins belonging to lipid biosynthesis (GO:0008610), lipid metabolism (GO: 0006629) and oligosaccharide metabolism (GO:0009311) were less abundant in the $\Delta c r t B$ mutant. Glycerophospholipids serve as the structural component of biological membranes and their alteration can affect physiology and adaptation ${ }^{39}$. Previously, we reported that the $\Delta c r t B$ mutant shows a modest increase in phosphatidylethanolamine (PE) head groups and unsaturated fatty acids when compared to wild type cells ${ }^{17}$. This observation could be the consequence of down regulation of lysophospholipase (PMI39_02976), which is important for glycerophospholipid metabolism ${ }^{40}$, in the $\Delta c r t B$ mutant. We also observed that a regulator of protease activity HflC, stomatin/ prohibitin superfamily-ybbK $(2,511,379,369)$ appeared less abundant in the $\Delta c r t B$ mutant, although the difference did not meet the criteria to be statistically significant ( $p$ value $=0.04$ but fold change =1.4). YbbK, encoded by PMI39_01287, belongs to the reggie (flotillin) superfamily, which includes eukaryotic flotillins and the bacterial homolog FlotP which was identified in Bacillus anthracis membrane microdomains ${ }^{25,41,42}$. The apparent reduction of YbbK in the carotenoid mutant is consistent with changes to microdomain organization, which may affect cellular functions such as protein signaling and transport. It is possible that the observed reduction of indole-3-acetic acid secretion and the decreased pellicle and biofilm formation observed in the $\Delta c r t B$ mutant results from changes in membrane domain architecture. 

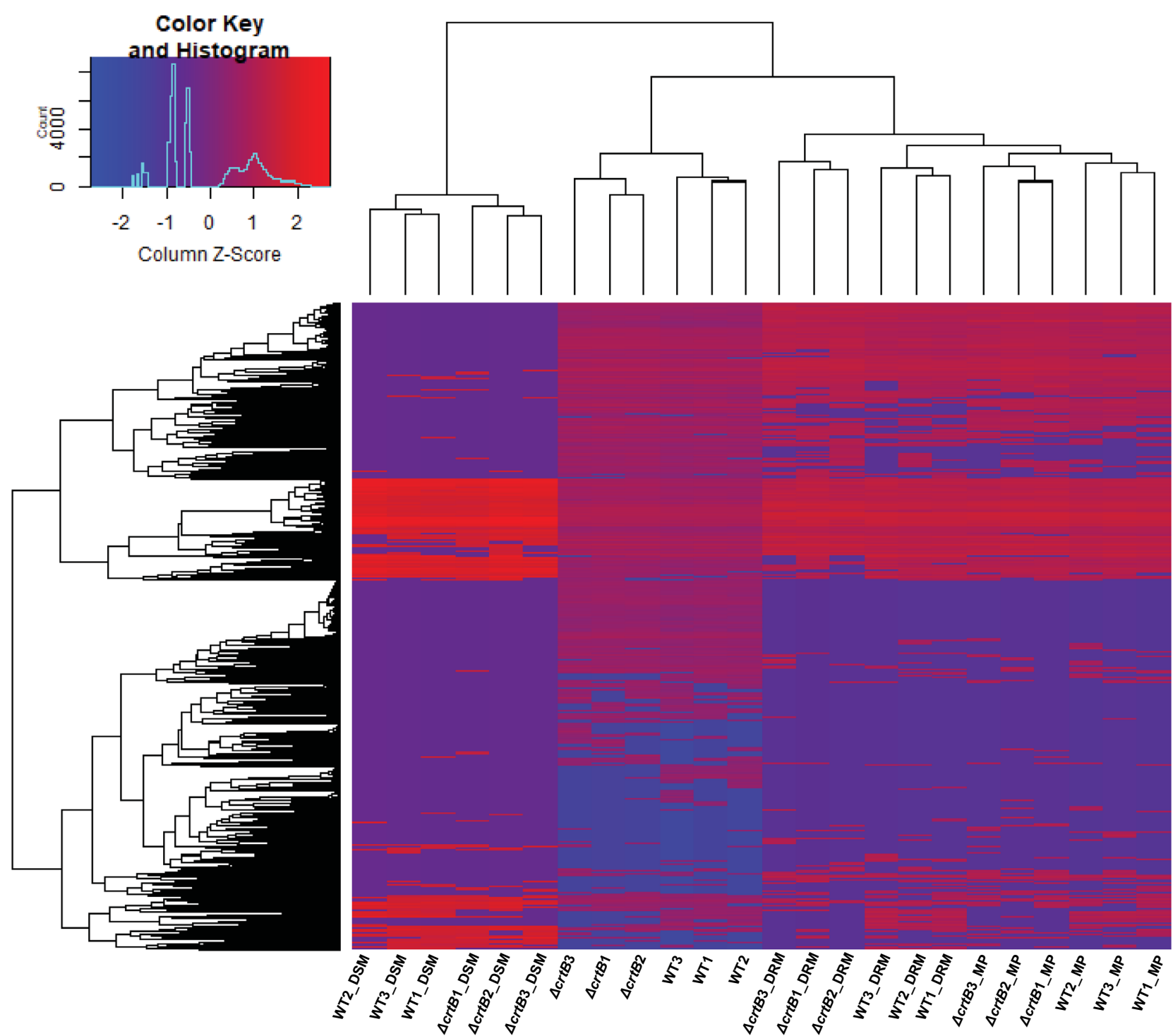

Figure 3. Hierarchical clustering of all proteins identified in Pantoea sp. YR343 wildtype and the $\Delta c r t B$ mutant. Heatmap of protein counts in Pantoea sp. YR343 wildtype and the $\Delta c r t B$ mutant indicate fraction specific abundance of proteins and differential abundance of proteins between wildtype and the $\Delta c r t B$ mutant. Higher protein abundance is indicated by red and lower protein abundance is indicated by blue. The heatmap was generated using gplots in Rstudio and scaled by column.

Other proteins such as tyrosine kinase $(2,511,379,927)$, cardiolipin synthase $(2,511,380,815)$ and phytoene desaturase $(2,511,381,490)$ were also less abundant in the $\Delta c r t B$ mutant whole cell fraction. Notably, four undecaprenyl phosphate proteins (Locus tags- PMI39_03112, PMI39_03113, PMI39_03114, PMI39_03115) in an operon involved in amino sugar and nucleotide sugar metabolism were less abundant in the $\Delta c r t B$ mutant $^{43}$. Undecaprenyl phosphate is a 55-carbon polyisoprenoid lipid involved in bacterial cell wall biogenesis by functioning as a lipid carrier, trafficking sugar intermediates across the plasma membrane ${ }^{44}$. There is also growing evidence that polyisoprenoids increase membrane fluidity and ion permeability ${ }^{45-48}$. The downregulation of this operon may explain, at least in part, the observed decrease in membrane fluidity in the $\Delta c r t B$ mutant ${ }^{17}$.

In the membrane fractions, several proteins with functional significance at the membrane were less abundant in the $\Delta c r t B$ mutant ( $p \leq 0.05$ and $F C \geq 2$ ). In particular, proteins belonging to envelope (GO:0030313), cell outer membrane (GO:0009279), membrane biogenesis, and cellular homeostasis were downregulated in the $\Delta c r t B$ mutant. Homeostasis is important for living organisms to maintain internal stability and it includes iron and metal homeostasis, membrane lipid homeostasis, and pH homeostasis. For example, TonB (PMI39_04701), an outer membrane receptor for ferrienterochelin and colicins, which are important for iron homeostasis ${ }^{49}$, was less abundant in the $\triangle c r t B$ DSM fraction.

Transcriptional analyses of the $\Delta c r t B$ mutant. The differences observed in the membrane proteomes between wildtype and the $\Delta c r t B$ mutant could be due to many factors, including differences in membrane pro- 
a

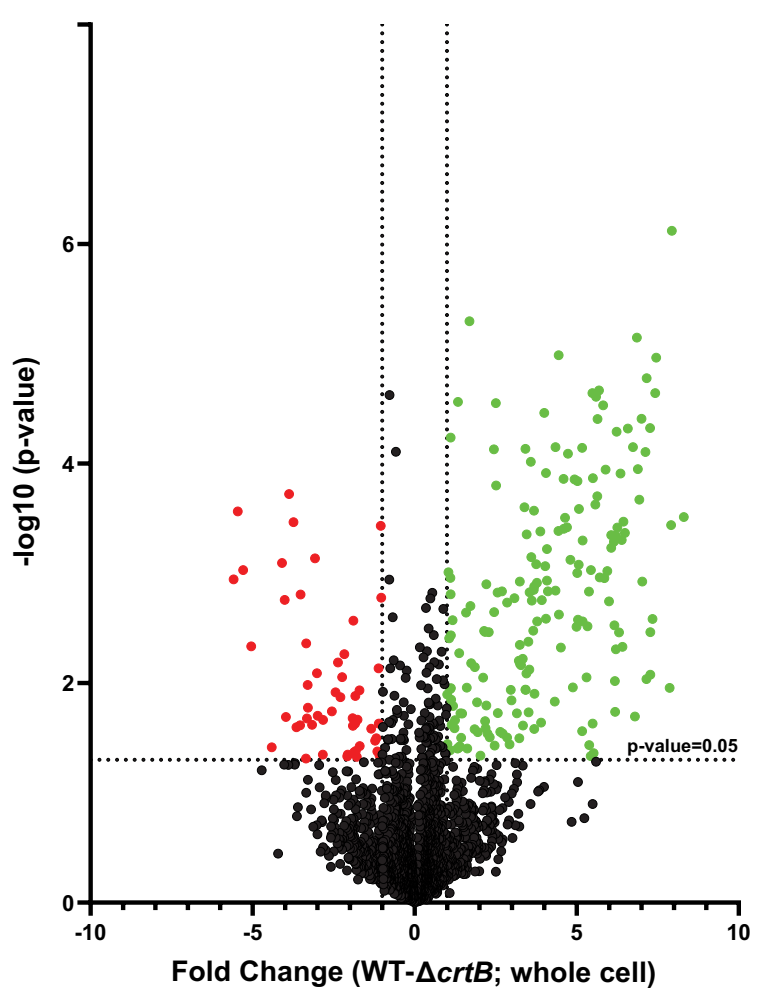

C

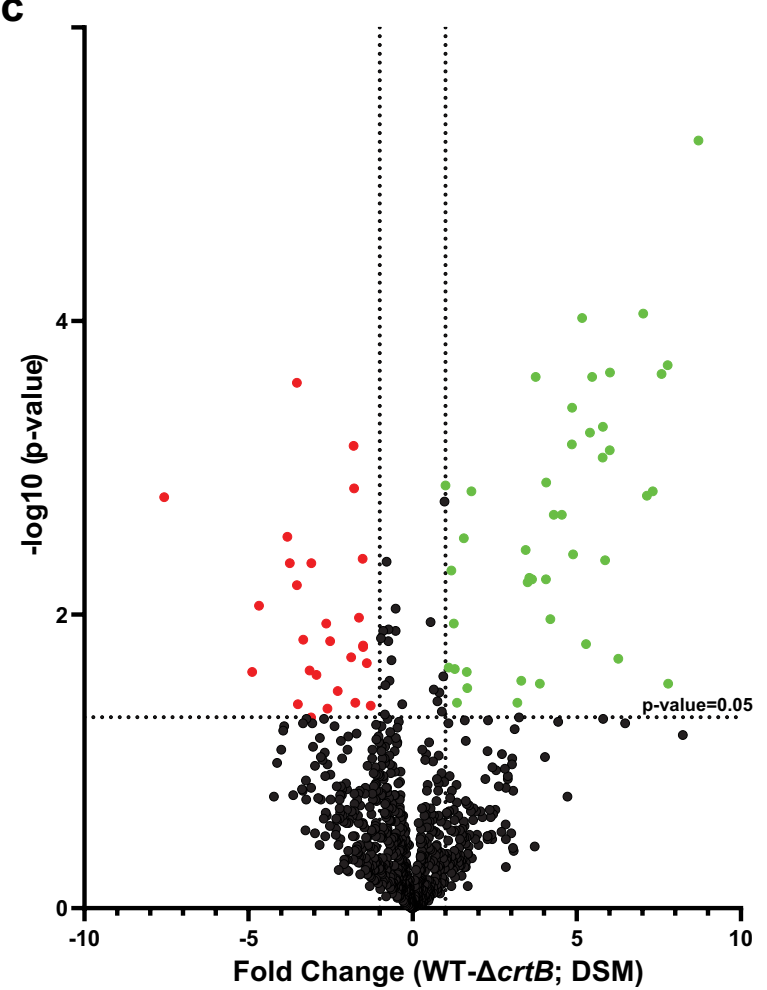

b

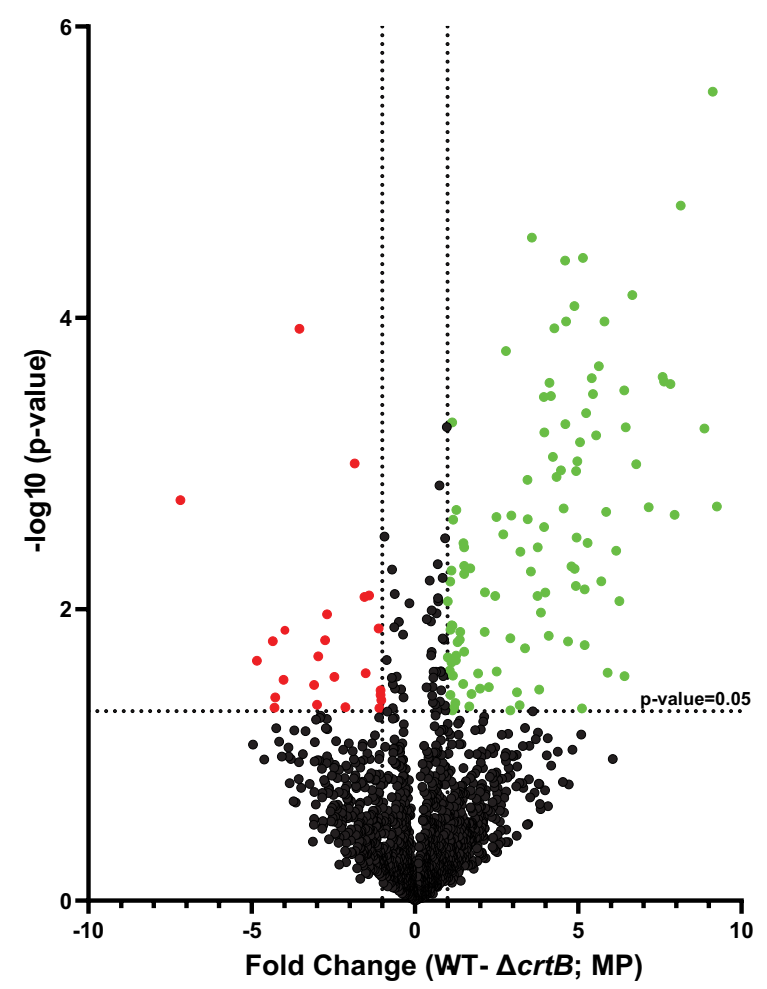

d

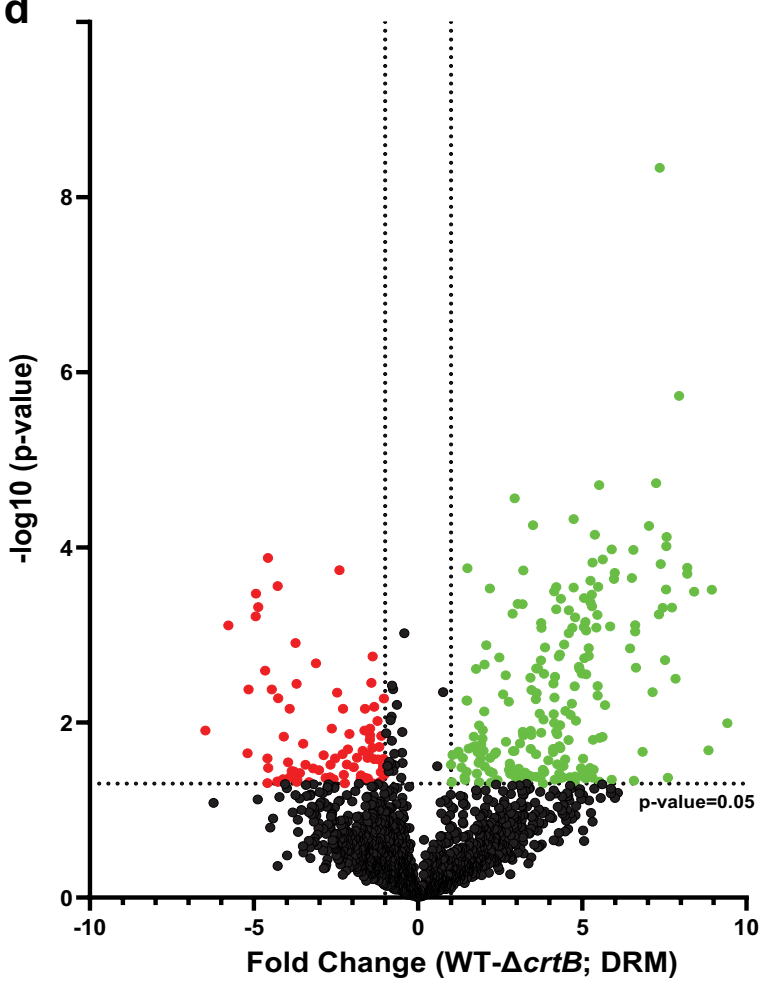

Figure 4. Volcano plots illustrating significantly differentially abundant proteins. The $-\log 10 p$ value (Benjamini-Hochberg corrected) (y-axis) is plotted against the fold change (x-axis) to identify significantly different proteins between sample types. Proteins with significantly increased (green) or decreased (red) abundance are shown for (a) Whole cell fraction; (b) Membrane pellet fraction; (c) DSM fraction; and (d) DRM fraction. The dashed line represents a significance level of $p \leq 0.05$ (Student's t-test). 


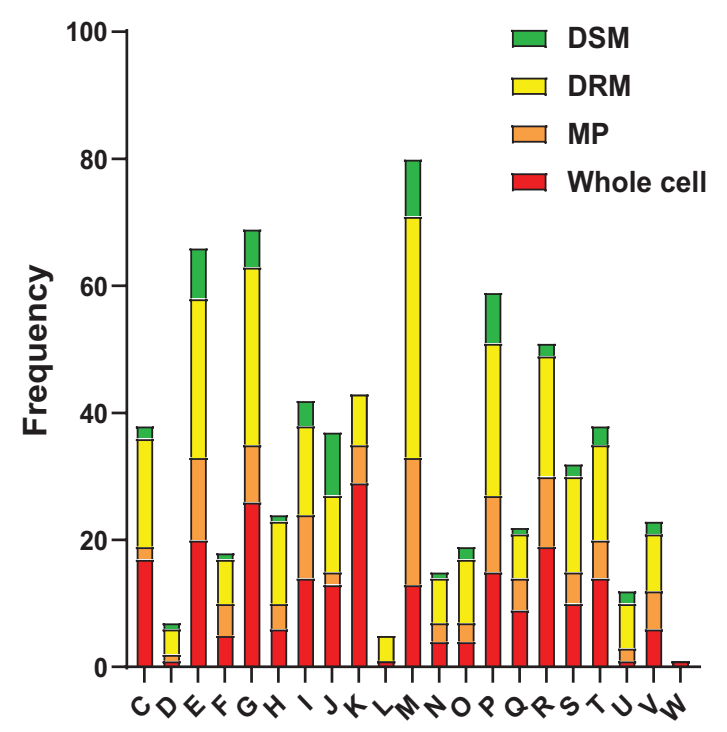

Figure 5. Top orthologous groups for all significant proteins in whole cell, membrane pellet, DRM and DSM samples. The functional classification of statistically significant proteins was organized according to COG assignments. The proteins in each COG category are proportioned based on the fraction in which they are differentially abundant with red indicating whole cell fraction, orange indicating membrane fraction, yellow indicating DRM fraction, and green indicating DSM fraction. The COG category labels are as follows: E-Amino acid transport and metabolism; G-Carbohydrate transport and metabolism; D-Cell cycle control, cell division, chromosome partitioning; N-Cell motility; M-Cell wall/membrane/envelope biogenesis; H-Coenzyme transport and metabolism; V-Defense mechanisms; C-Energy production and conversion; W-Extracellular structures; S-Function unknown R-General function prediction only; P-Inorganic ion transport and metabolism; U-Intracellular trafficking, secretion, and vesicular transport; I-Lipid transport and metabolism; F-Nucleotide transport and metabolism; O-Post-translational modification, protein turnover, and chaperones; L-Replication, recombination and repair; Q-Secondary metabolites biosynthesis, transport, and catabolism; T-Signal transduction mechanisms; K-Transcription; J-Translation, ribosomal structure and biogenesis.

tein insertion and stability, localization, or abundance. To better understand the basis for the observed differences, we performed transcriptional analyses to examine which gene products are transcriptionally regulated. Differentially expressed transcripts between the wildtype and $\Delta c r t B$ mutant samples were identified using KBase tools as described in the methods ${ }^{50}$. Only 5 transcripts were significantly upregulated ( $p$ value $\leq 0.05$ and FC $\geq 2$ ), whereas 879 transcripts were significantly downregulated in the $\Delta c r t B$ mutant (Supplemental Table 1). Heat maps representing the differential expression profile of wildtype and $\Delta c r t B$ mutant are shown in Fig. 6 . Detailed comparisons of the protein abundances and transcriptional regulation were performed for selected functional categories.

Cell wall/membrane/envelope biogenesis. Proteins predicted to be involved in cell wall/membrane/ envelope biogenesis (270 proteins total, COG category M) in Pantoea sp. YR343 were collected from the JGI IMG database. Table 2 lists all the proteins $(p \leq 0.005$ and $\mathrm{FC} \geq 1)$ involved in cell membrane biogenesis that were significantly differentially abundant in at least one fraction (56 total). Among these proteins, six undecaprenyl-phosphate (UDP) proteins belonging to peptidoglycan/lipopolysaccharide biosynthesis were found to be significantly less abundant in the $\Delta c r t B$ mutant (PMI39_01550, PMI39_02251, PMI39_03115, PMI39_01848, PMI39_03114, PMI39_04793). UDP gene products are involved in exopolysaccharide secretion, cationic antimicrobial peptide resistance, lipid A biogenesis, and peptidoglycan synthesis ${ }^{44}$ and most were found in the DRM fractions. Transcript data for two of the UDP proteins, undecaprenyl-phosphate 4-deoxy-4-formamido-Larabinose transferase (PMI39_03114) and UDP-4-amino-4-deoxy-L-arabinose-oxoglutarate aminotransferase (PMI39_03115), showed downregulation at the transcript level in the $\Delta c r t B$ mutant (Table 2). Downregulation of these UDP genes may explain the observed differences in the peptidoglycan layer of the $\Delta c r t B$ mutant in comparison to the wildtype ${ }^{17}$. Another protein, UDP-galactose-lipid carrier transferase (PMI39_01848), has a transmembrane domain and was found to be less abundant in the mutant DRM fraction. The gene encoding this protein is the first gene in a large operon that shows significant similarity to operons involved in EPS biosynthesis in the related plant-associated microbes Erwinia amylovora and Pantoea stewartii ${ }^{51,52}$. It is possible that the reduction in this protein decreases EPS production in the $\Delta c r t B$ mutant, which may contribute to the defects associated with biofilm formation and plant colonization.

Outer membrane proteins (OMP) are important for transport of metabolites and toxins, membrane biogenesis, and for bacterial resistance. The folding and insertion of several OMPs are carried out by BamA along with three lipoproteins: BamB, BamC, and BamE forming the BAM machine (beta-barrel assembly) ${ }^{53,54}$. Lipoproteins are peripherally anchored membrane proteins involved in cell division, chemotaxis, signal transduction and 
GO term

Ontology source

No. of genes

Whole-cell pairwise-down-regulated in $\Delta \mathrm{crtB}$

\begin{tabular}{|l|l|}
\hline GO:0044264 & Cellular polysaccharide metabolic process \\
\hline GO:0009311 & Oligosaccharide metabolic process \\
\hline GO:0006629 & Lipid metabolic process \\
\hline GO:0008610 & Lipid biosynthetic process \\
\hline GO:0016798 & Hydrolase activity, acting on glycosyl bonds \\
\hline GO:0004553 & Hydrolase activity, hydrolyzing O-glycosyl compounds \\
\hline GO:0015926 & Glucosidase activity \\
\hline GO:0090599 & Alpha-glucosidase activity \\
\hline GO:0016903 & Oxidoreductase activity, acting on the aldehyde or oxo group of donors \\
\hline GO:0019695 & Choline metabolic process \\
\hline GO:0031455 & Glycine betaine metabolic process \\
\hline GO:0006578 & Amino-acid betaine biosynthetic process \\
\hline GO:0019285 & Glycine betaine biosynthetic process from choline \\
\hline GO:0031456 & Glycine betaine biosynthetic process \\
\hline GO:0008802 & Betaine-aldehyde dehydrogenase activity \\
\hline
\end{tabular}

GO_BiologicalProcess

GO_BiologicalProcess

GO_BiologicalProcess

GO_BiologicalProcess

GO_MolecularFunction

GO_MolecularFunction

GO_MolecularFunction

GO_MolecularFunction

GO_MolecularFunction

GO_BiologicalProcess

GO_BiologicalProcess

GO_BiologicalProcess

GO_BiologicalProcess

GO_BiologicalProcess

GO_MolecularFunction

Whole-cell pairwise-up-regulated in $\Delta \mathrm{crtB}$

\begin{tabular}{|l|l|l|}
\hline GO:0006260 & DNA replication & GO \\
\hline GO:0050790 & Regulation of catalytic activity & GO \\
\hline GO:1901698 & Response to nitrogen compound & C \\
\hline MP pairwise- & down-regulated in $\Delta$ crtB &
\end{tabular}

GO_BiologicalProcess

GO_BiologicalProcess

GO_BiologicalProcess

GO:0031241 $\quad$ Periplasmic side of cell outer membrane

\begin{tabular}{l|l}
\hline GO:0031975 & Envelope \\
\hline
\end{tabular}

\begin{tabular}{|l|l}
\hline GO:0030312 & External encapsulating structure \\
\hline
\end{tabular}

GO:0030313 Cell envelope

\begin{tabular}{|l|l}
\hline GO:0044462 & External encapsulating structure part \\
\hline GO:0009279 & Cellour
\end{tabular}

GO:0009279 $\quad$ Cell outer membrane

DRM pairwise-down-regulated in $\Delta \mathrm{crtB}$

\begin{tabular}{|l|l|l|c|}
\hline GO:0048038 & Quinone binding & GO_MolecularFunction & 8 \\
\hline GO:0071944 & Cell periphery & GO_CellularComponent & 139 \\
\hline GO:0008104 & Protein localization & GO_BiologicalProcess & 17 \\
\hline GO:1904659 & Glucose transmembrane transport & GO_BiologicalProcess & 4 \\
\hline GO:0030001 & Metal ion transport & GO_BiologicalProcess & 15 \\
\hline GO:0022804 & Active transmembrane transporter activity & GO_MolecularFunction & 33 \\
\hline GO:0055085 & Transmembrane transport & GO_BiologicalProcess & 49 \\
\hline GO:0031224 & Intrinsic component of membrane & GO_CellularComponent & 104 \\
\hline GO:0005886 & Plasma membrane & GO_CellularComponent & 120 \\
\hline GO:0016021 & Integral component of membrane & GO_CellularComponent & 99 \\
\hline GO:0044459 & Plasma membrane part & GO_CellularComponent & 73 \\
\hline GO:0031226 & Intrinsic component of plasma membrane & GO_CellularComponent & 63 \\
\hline GO:0005887 & Integral component of plasma membrane & GO_CellularComponent & 61 \\
\hline GO:0031975 & Envelope & GO_CellularComponent & 31 \\
\hline GO:0098552 & Side of membrane & GO_CellularComponent & 14 \\
\hline GO:0030312 & External encapsulating structure & GO_CellularComponent & 23 \\
\hline GO:0030313 & Cell envelope & GO_CellularComponent & 26 \\
\hline GO:0044462 & External encapsulating structure part & GO_CellularComponent & 19 \\
\hline GO:0009279 & Cell outer membrane & GO_CellularComponent & 19 \\
\hline GO:0031230 & Intrinsic component of cell outer membrane & GO_CellularComponent & 7 \\
\hline GO:0031241 & Periplasmic side of cell outer membrane & GO_CellularComponent & 7 \\
\hline DRM pairwise- - up-regulated in $\Delta$ crtB & & & \\
\hline GO:0005829 & Cytosol & GO_CellularComponent & 45 \\
\hline GO:0006090 & Pyruvate metabolic process & GO_BiologicalProcess & 6 \\
\hline GO:0043168 & Anion binding & GO_MolecularFunction & 28 \\
\hline GO:0032553 & Ribonucleotide binding & GO_MolecularFunction & 21 \\
\hline GO:0030554 & Adenyl nucleotide binding & GO_MolecularFunction & 18 \\
\hline GO:0032559 & Adenyl ribonucleotide binding & & 18 \\
\hline Continued & & \\
\hline
\end{tabular}

GO_CellularComponent 4 GO_CellularComponent 21 GO_CellularComponent 16 GO_CellularComponent 19 GO_CellularComponent GO_CellularComponent

GO_MolecularFunction $\quad 8$

139

GO_MolecularFunction

GO_CellularComponent

GO_CellularComponen

ularComponent

GO_CellularComponen

O_BiologicalProces

4

4

(6)

9

12

12

4

$+2$




\begin{tabular}{|c|c|c|c|}
\hline GOID & GO term & Ontology source & No. of genes \\
\hline GO:0006082 & Organic acid metabolic process & GO_BiologicalProcess & 28 \\
\hline GO:0044283 & Small molecule biosynthetic process & GO_BiologicalProcess & 22 \\
\hline GO:0016053 & Organic acid biosynthetic process & GO_BiologicalProcess & 16 \\
\hline GO:0043436 & Oxoacid metabolic process & GO_BiologicalProcess & 28 \\
\hline GO:1901566 & Organonitrogen compound biosynthetic process & GO_BiologicalProcess & 25 \\
\hline GO:0019752 & Carboxylic acid metabolic process & GO_BiologicalProcess & 27 \\
\hline GO:0046394 & Carboxylic acid biosynthetic process & GO_BiologicalProcess & 16 \\
\hline \multicolumn{4}{|c|}{ DSM pairwise-down-regulated in $\Delta$ crtB } \\
\hline GO:1903509 & Liposaccharide metabolic process & GO_BiologicalProcess & 4 \\
\hline GO:0030312 & External encapsulating structure & GO_CellularComponent & 10 \\
\hline GO:0015850 & Organic hydroxy compound transport & GO_BiologicalProcess & 3 \\
\hline GO:0022838 & Substrate-specific channel activity & GO_MolecularFunction & 3 \\
\hline GO:0019725 & Cellular homeostasis & GO_BiologicalProcess & 3 \\
\hline GO:0048878 & Chemical homeostasis & GO_BiologicalProcess & 3 \\
\hline GO:0005783 & Endoplasmic reticulum & GO_CellularComponent & 3 \\
\hline GO:0046873 & Metal ion transmembrane transporter activity & GO_MolecularFunction & 4 \\
\hline GO:0030001 & Metal ion transport & GO_BiologicalProcess & 5 \\
\hline GO:0072511 & Divalent inorganic cation transport & GO_BiologicalProcess & 3 \\
\hline GO:0000041 & Transition metal ion transport & GO_BiologicalProcess & 4 \\
\hline GO:0070838 & Divalent metal ion transport & GO_BiologicalProcess & 3 \\
\hline \multicolumn{4}{|c|}{ DSM pairwise-up-regulated in $\Delta \mathrm{crtB}$} \\
\hline GO:0045229 & External encapsulating structure organization & GO_BiologicalProcess & 3 \\
\hline GO:0015293 & Symporter activity & GO_MolecularFunction & 3 \\
\hline GO:0022613 & Ribonucleoprotein complex biogenesis & GO_BiologicalProcess & 6 \\
\hline GO:0003723 & RNA binding & GO_MolecularFunction & 8 \\
\hline GO:0042254 & Ribosome biogenesis & GO_BiologicalProcess & 6 \\
\hline GO:0044446 & Intracellular organelle part & GO_CellularComponent & 11 \\
\hline GO:0070925 & Organelle assembly & GO_BiologicalProcess & 4 \\
\hline GO:0071826 & Ribonucleoprotein complex subunit organization & GO_BiologicalProcess & 4 \\
\hline GO:0006518 & Peptide metabolic process & GO_BiologicalProcess & 9 \\
\hline GO:0042273 & Ribosomal large subunit biogenesis & GO_BiologicalProcess & 3 \\
\hline GO:0043232 & Intracellular non-membrane-bounded organelle & GO_CellularComponent & 9 \\
\hline GO:0005840 & Ribosome & GO_CellularComponent & 9 \\
\hline GO:0019843 & rRNA binding & GO_MolecularFunction & 7 \\
\hline GO:0022618 & Ribonucleoprotein complex assembly & GO_BiologicalProcess & 4 \\
\hline GO:0034622 & Cellular protein-containing complex assembly & GO_BiologicalProcess & 4 \\
\hline GO:0043604 & Amide biosynthetic process & GO_BiologicalProcess & 9 \\
\hline GO:0043043 & Peptide biosynthetic process & GO_BiologicalProcess & 9 \\
\hline GO:0044391 & Ribosomal subunit & GO_CellularComponent & 9 \\
\hline GO:0006412 & Translation & GO_BiologicalProcess & 9 \\
\hline GO:0042255 & Ribosome assembly & GO_BiologicalProcess & 4 \\
\hline GO:0044445 & Cytosolic part & GO_CellularComponent & 9 \\
\hline GO:0000027 & Ribosomal large subunit assembly & GO_BiologicalProcess & 3 \\
\hline GO:0015934 & Large ribosomal subunit & GO_CellularComponent & 8 \\
\hline GO:0022626 & Cytosolic ribosome & GO_CellularComponent & 9 \\
\hline GO:0006364 & rRNA processing & GO_BiologicalProcess & 3 \\
\hline GO:0016072 & rRNA metabolic process & GO_BiologicalProcess & 3 \\
\hline GO:0022625 & Cytosolic large ribosomal subunit & GO_CellularComponent & 8 \\
\hline
\end{tabular}

Table 1. Whole-genome gene ontology (GO) term annotation using Blast2GO software. Whole gene ontology was performed using Blast2GO with a Blastp E-value hit filter of $1 \times 10^{-5}$ and annotation cutoff value of 55 and a GO weight of 5 . Using ClueGO, observed GO biological process were subjected to the right-sided hypergeometric enrichment test at medium network specificity selection and $p$ value correction was performed using the Holm-Bonferroni step-down method. 

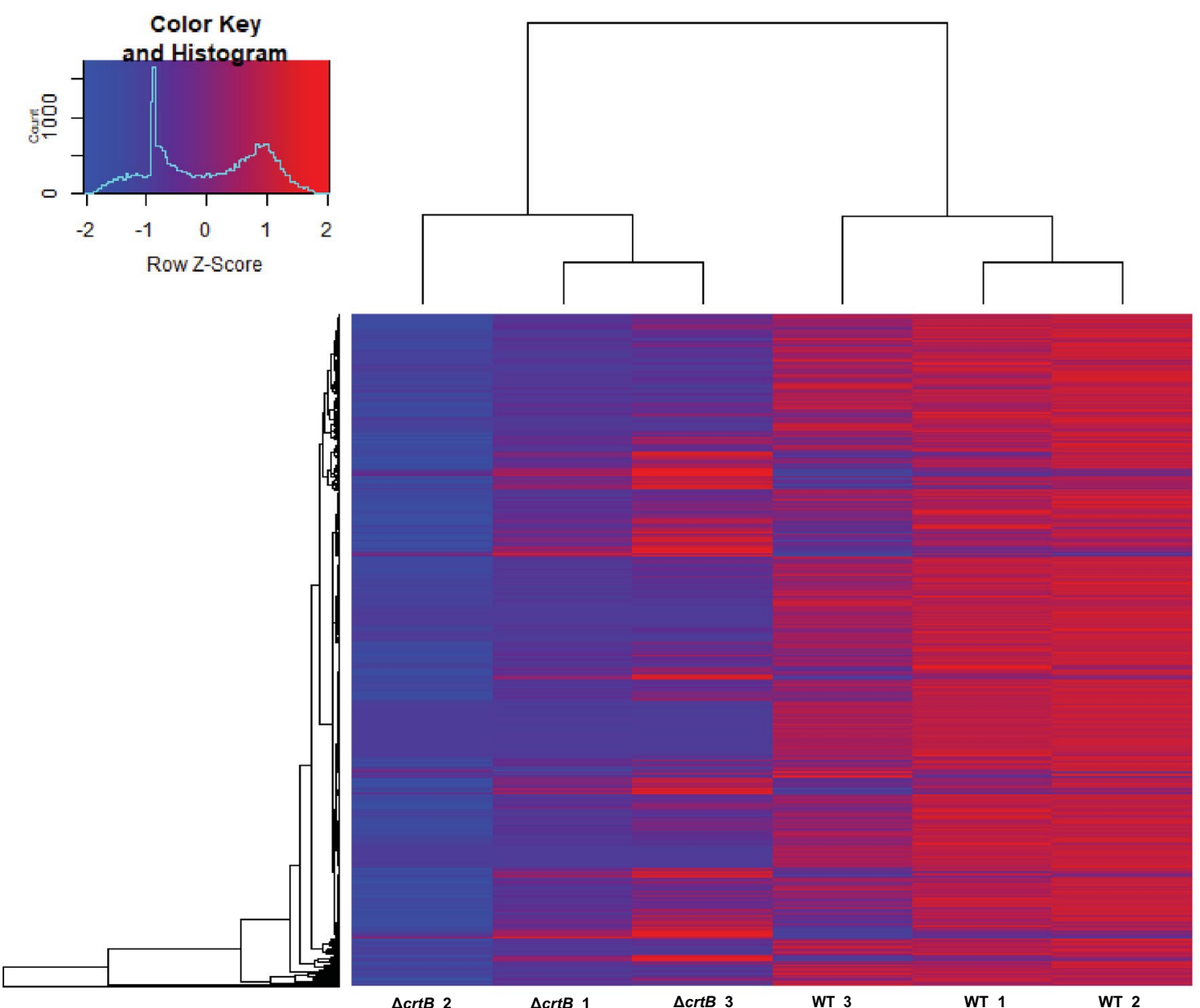

Figure 6. Clustered heatmap of gene expression in Pantoea sp. YR343 and the $\Delta c r t B$ mutant. Hierarchical clustering was performed using absolute transcript counts. Genome wide transcriptional signatures indicated generally lower expression profiles in the $\Delta c r t B$ mutant compared to the wildtype. Higher transcript levels are shown in red and lower transcript numbers are shown in blue. The heatmap was generated using gplots in Rstudio and scaled by row.

envelope stability ${ }^{55-57}$. Among the 4 Bam proteins, BamA (PMI39_03681) and BamB (PMI39_03586) were found to be less abundant in the $\Delta c r t B$ mutant (Table 2). BamB was identified in both the membrane pellet and the DRM fraction. Studies have shown that BamB contains WD40 repeating units, thereby functioning as a scaffold protein in large multi-protein complexes ${ }^{58}$. It was also shown that the Bam complex increases the efficiency of folding of membrane proteins such as OmpA and EspP $P^{59}$. We also found that the Skp protein (PMI39_3680) was more abundant in the $\triangle \operatorname{crtB}$ mutant DSM fraction. Skp is a multivalent periplasmic chaperone preventing misfolding and aggregation of OMPs, such as OmpA, during transit from the inner to the outer membranes ${ }^{60}$. The changes in membrane fluidity, lipid content, and the lack of carotenoids in the $\Delta c r t B$ mutant may influence assembly of the Bam complex at the outer membrane, leading to misfolding of other OMPs, but not affect localization or function of the periplasmic Skp protein. Thus, the increased abundance of Skp in the $\Delta c r t B$ mutant may be a compensatory mechanism to maintain proper folding of proteins to protect the integrity of the cell.

Cell motility (N). Beyond the defects in IAA secretion, biofilm formation, and root colonization previously reported $^{29}$, we also observed that the $\Delta c r t B$ mutant appeared to be less motile than wildtype on swimming motility plates (Fig. 7a). To further characterize this defect, we compared motility patterns of wildtype and mutant cells by microscopy. We found that the average mean speed was $3.5 \mu \mathrm{m} / \mathrm{s}$ for the $\Delta \operatorname{crt} B$ mutant which was significantly reduced compared to $4.9 \mu \mathrm{m} / \mathrm{s}$ for wild type cells (Fig. $7 \mathrm{~b}$ ). Moreover, flagella staining and quantification using ImageJ indicated that the $\Delta c r t B$ mutant had significantly shorter flagella when compared to wildtype (Fig. 7c). The average flagellar length for the wildtype cells were $7.4 \mu \mathrm{m}$ whereas the $\Delta c r t B$ mutant flagella measured $2.8 \mu \mathrm{m}$ (Fig. 7d). To help explain the motility defect, we examined the 92 proteins predicted to be involved in cell motility, of which 18 were differentially abundant in the mutant compared to wildtype (Table 3 ). Among the 28 proteins that form the flagellar complex ${ }^{61}$, only 3 proteins: flagellar FliL (PMI39_02182) and two flagellar hookassociated protein 2 (PMI39_02605 and PMI39_02159) were significantly less abundant in the $\Delta c r t B$ mutant and only one of these, PMI39_02605, was significantly downregulated based on the transcriptomic data (Table 3). In Salmonella and E. coli, it was shown that FliL interacts closely with stators and the MS ring, ensuring delivery of 


\begin{tabular}{|c|c|c|c|c|c|c|c|}
\hline \multicolumn{8}{|c|}{ Cell wall/Membrane/envelope biogenesis } \\
\hline Locus Tag & Gene Product Name & TM/SP & $\begin{array}{c}\text { Whole } \\
\text { cell }\end{array}$ & $\begin{array}{c}\text { Membrane } \\
\text { pellet }\end{array}$ & DRM & DSM & Transcriptomes \\
\hline PMI39 01845 & tyrosine-protein kinase Etk/Wzc & TM & & & & & \\
\hline PMI39 04919 & RND family efflux transporter, MFP subunit & & & & & & \\
\hline PMI39_01315 & $\begin{array}{l}\text { membrane fusion protein, multidrug efflux } \\
\text { system }\end{array}$ & SP & & & & & \\
\hline PMI39 03114 & $\begin{array}{l}\text { undecaprenyl-phosphate 4-deoxy-4- } \\
\text { formamido-L-arabinose transferase }\end{array}$ & TM & & & & & \\
\hline PMI39_04116 & ADP-heptose:LPS heptosyltransferase & & & & & & \\
\hline PMI39 04793 & $\begin{array}{l}\text { undecaprenyl-phosphate galactose } \\
\text { phosphotransferase }\end{array}$ & TM & & & & & \\
\hline PMI39_00342 & Nucleoside-diphosphate-sugar epimerase & & & & & & \\
\hline PMI39_03115 & $\begin{array}{l}\text { UDP-4-amino-4-deoxy-L-arabinose- } \\
\text { oxoglutarate aminotransferase }\end{array}$ & & & & & & \\
\hline PMI39_04095 & aspartate racemase & & & & & & \\
\hline PMI39_00324 & 4-hydroxy-tetrahydrodipicolinate synthase & & & & & & \\
\hline PMI39_02352 & glucose-1-phosphate thymidylyltransferase & & & & & & \\
\hline PMI39_02560 & xylose isomerase & & & & & & \\
\hline PMI39_01126 & hypothetical protein & SP & & & & & \\
\hline PMI39_03339 & penicillin-binding protein $1 \mathrm{~A}$ & TM & & & & & \\
\hline PMI39_03586 & Beta-barrel assembly machine subunit BamB & & & & & & \\
\hline PMI39_01060 & outer membrane protein & SP & & & & & \\
\hline PMI39_03111 & 4-amino-4-deoxy-L-arabinose transferase & TM & & & & & \\
\hline PMI39_04302 & lipid A ethanolaminephosphotransferase & TM & & & & & \\
\hline PMI39 01643 & $\begin{array}{l}\text { membrane-bound lytic murein transglycosylase } \\
\text { B }\end{array}$ & SP & & & & & \\
\hline PMI39 01850 & AsmA protein & TM & & & & & \\
\hline PMI39_03681 & Beta-barrel assembly machine subunit BamA & SP & & & & & \\
\hline PMI39_00306 & $\begin{array}{l}\text { membrane fusion protein, macrolide-specific } \\
\text { efflux system }\end{array}$ & TM & & & & & \\
\hline PMI39 04772 & $\mathrm{~N}$-acetylmuramoyl-L-alanine amidase & & & & & & \\
\hline PMI39 00593 & $\begin{array}{l}\text { D-alanyl-D-alanine carboxypeptidase } \\
\text { (penicillin-binding protein } 5 / 6 \text { ) }\end{array}$ & & & & & & \\
\hline PMI39 00843 & murein lipoprotein & SP & & & & & \\
\hline PMI39_00870 & hypothetical protein & $\mathrm{SP}$ & & & & & \\
\hline PMI39_00927 & membrane glycosyltransferase & TM & & & & & \\
\hline PMI39_01154 & $\begin{array}{l}\text { autotransporter secretion outer membrane } \\
\text { protein TamA }\end{array}$ & SP & & & & & \\
\hline PMI39_01192 & Apolipoprotein N-acyltransferase & TM & & & & & \\
\hline PMI39 01206 & rare lipoprotein $\mathrm{A}$ & & & & & & \\
\hline PMI39_01207 & $\begin{array}{l}\text { D-alanyl-D-alanine carboxypeptidase } \\
\text { (penicillin-binding protein } 5 / 6 \text { ) }\end{array}$ & SP & & & & & \\
\hline PMI39 01510 & lipoprotein NlpI & & & & & & \\
\hline PMI39 01562 & $\begin{array}{l}\text { lipopolysaccharide export system ATP-binding } \\
\text { protein }\end{array}$ & & & & & & \\
\hline PMI39 01583 & apolipoprotein D and lipocalin family protein & SP & & & & & \\
\hline PMI39_01648 & lipoprotein NlpD & SP & & & & & \\
\hline PMI39 01840 & $\begin{array}{l}\text { Glycosyltransferase involved in cell wall } \\
\text { bisynthesis }\end{array}$ & & & & & & \\
\hline PMI39 01848 & UDP-galactose-lipid carrier transferase & TM & & & & & \\
\hline PMI39 01858 & $\begin{array}{l}\text { membrane fusion protein, multidrug efflux } \\
\text { system }\end{array}$ & $\mathrm{TM}$ & & & & & \\
\hline PMI39 02251 & $\begin{array}{l}\text { UDP-D-galactose:(glucosyl) LPS alpha-1,3-D- } \\
\text { galactosyltransferase }\end{array}$ & & & & & & \\
\hline
\end{tabular}

(continued) 


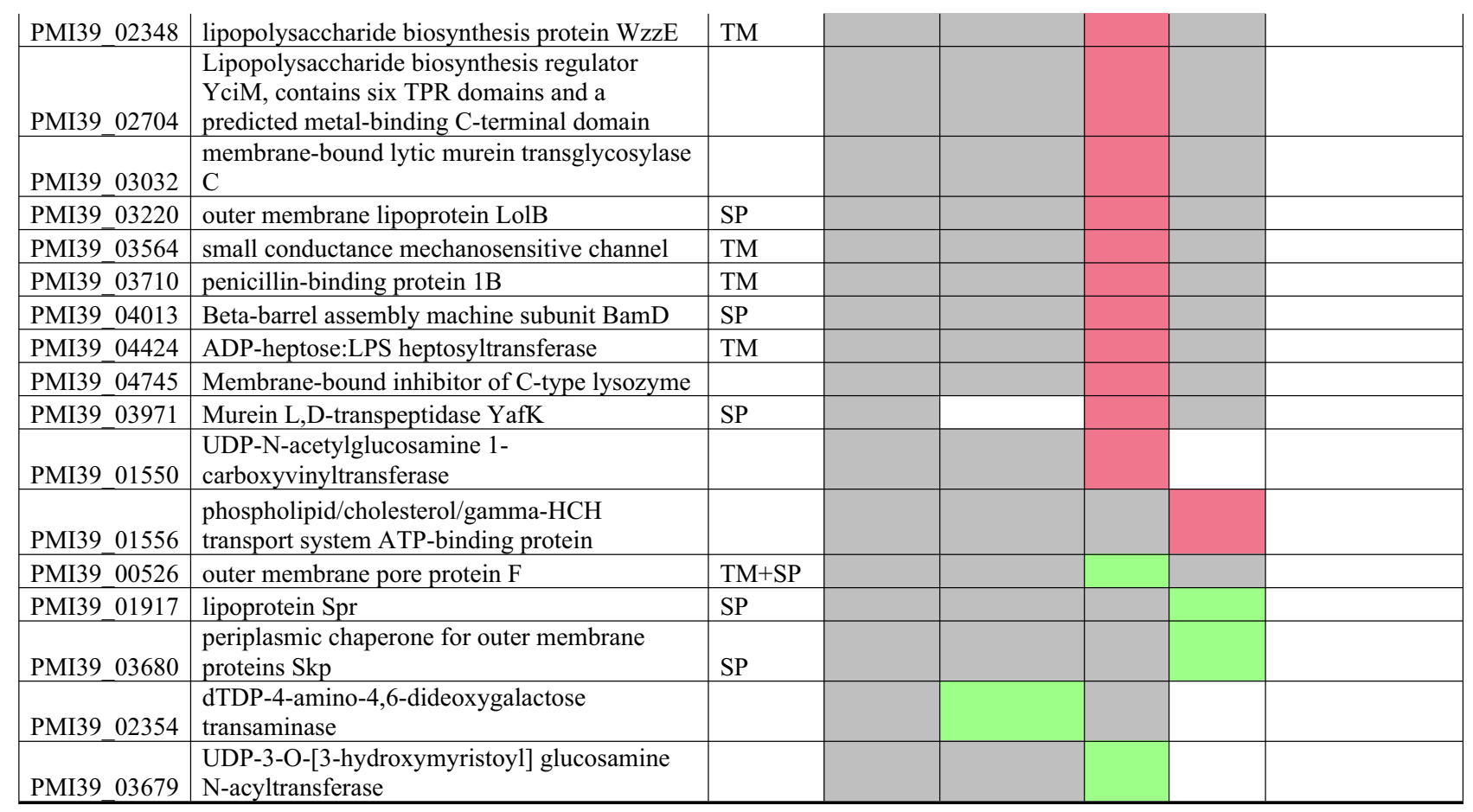

\begin{tabular}{|c|}
\hline$\backslash \Delta c r t B$ \\
\hline$\backslash \Delta c r t B$ \\
\hline Not significant \\
\hline Not detected \\
\hline
\end{tabular}

Table 2. List of significantly differentially abundant proteins involved in cell wall/membrane/ envelope biogenesis. Protein list from JGI for each COG category was matched with the proteomics dataset and only proteins that were significantly different in at least one fraction of the wildtype or $\Delta c r t B$ mutant are reported. TM/SP- proteins with transmembrane helices or signal peptide. Red: proteins that are significantly less abundant in the $\Delta c r t B$ mutant, green: proteins that are significantly more abundant in the $\Delta c r t B$ mutant, grey: nonsignificant proteins and white: proteins that are not detected.

higher torque, leading to increased motility ${ }^{62}$. In the absence of the FliL protein, single motors have been shown to rotate at lower speeds ${ }^{62,63}$. It is possible that the changes in membrane lipid composition and/or organization affect assembly or function of the flagellar motor apparatus, leading to the observed motility defects.

In addition to the proteins involved in the flagellar motor apparatus, we also found differences in protein abundance and transcriptional regulation of several methyl-accepting chemotaxis proteins (MCP) in the $\Delta c r t B$ mutant compared to wild type (Table 3). MCPs undergo reversible methylation in response to changes in the concentration of attractants or repellents in their environment ${ }^{64}$. Interestingly, two MCP proteins, encoded by PMI39_02297 and PMI39_01148, were found to be more abundant in the $\Delta c r t B$ whole cell fraction, whereas the MCP encoded by PMI39_02163 was found to be more abundant in the $\triangle c r t B$ DRM fraction. This increased abundance in the $\triangle c r t B$ mutant did not appear to be due to transcriptional upregulation (Table 3). Additional experiments are needed to distinguish whether these proteins are differentially localized, more stable, or perhaps more easily extracted from the $\Delta c r t B$ mutant.

Lipid transport and metabolism (I). In Pantoea sp. YR343, 150 proteins are found in the lipid transport and metabolism COG category I, of which 26 proteins were found to be significantly abundant in at least one fraction (Table 4). Two choline dehydrogenases (encoded by PMI39_02890 and PMI39_00318) were significantly more abundant in all or most fractions of the $\Delta c r t B$ mutant. Surprisingly, however, these genes were transcriptionally downregulated (Table 4). Choline dehydrogenase catalyzes the first step in glycine betaine synthesis to produce the final compound betaine, an effective osmoprotectant ${ }^{65,66}$. It is possible that the lipid composition or membrane organization in the carotenoid mutant promotes choline dehydrogenase protein stability or, alternatively, promotes its efficient extraction. Other proteins such as lysophospholipase (PMI39_01261, PMI39_04916) and NAD(P) dependent dehydrogenasese (PMI39_04227, PMI39_04693, PMI39_04133) were also more abundant in the $\Delta c r t B$ mutant.

Cyclopropane-fatty-acyl-phospholipid synthase (PMI39_04767) and predicted lipid carrier protein YhbT, containing a SCP2 domain (PMI39_01503), were less abundant in the $\Delta c r t B$ DRM fractions. The physiological 
a

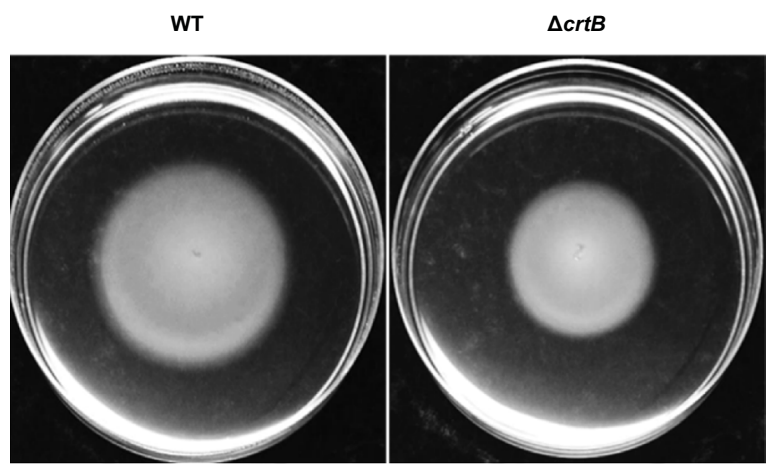

C
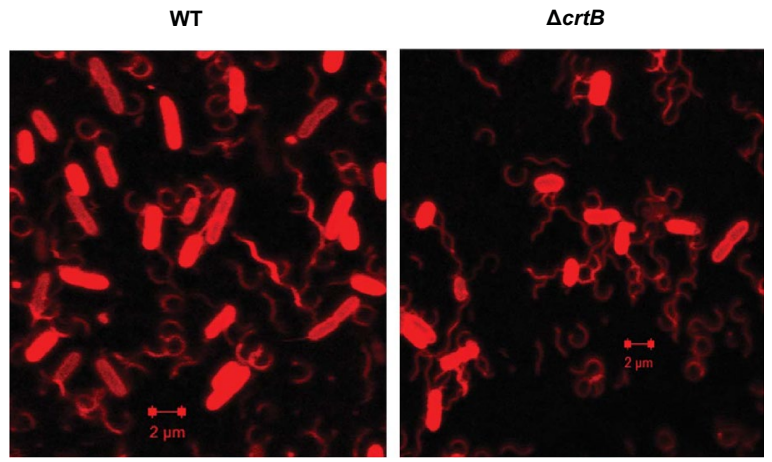

b
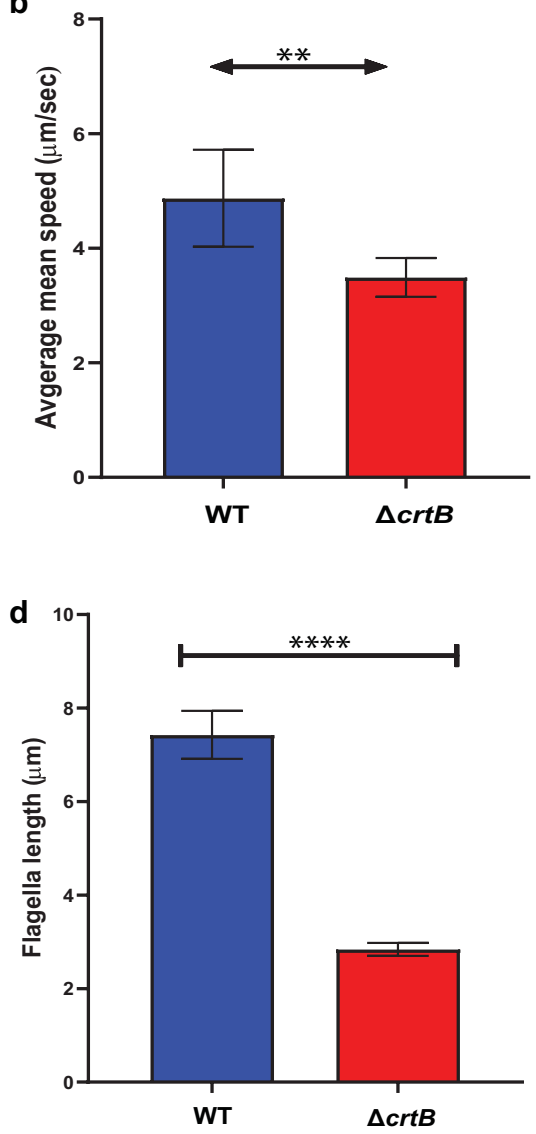

Figure 7. Loss of carotenoids affects bacterial cell motility. (a) Swimming motility of wildtype and the $\Delta c r t B$ mutant on LB plates with $0.3 \%$ agar. Cells were inoculated at the center of the plate from an overnight culture and photographed after $16 \mathrm{~h}$ incubation at $28^{\circ} \mathrm{C}$. (b) Cells from motility plates were grown to $\mathrm{OD}_{600}$ of 0.5 and swimming motility videos of 10 biological replicates were collected and processed by ImageJ. (c) Flagella staining with Alexa Fluor 594 carboxylic acid succinimidyl ester was carried out on log-phase cells and imaged using confocal microscopy. (d) Flagellar length measurement $(\mu \mathrm{m})$ of 30 wildtype and $\Delta c r t B$ mutant cells using ImageJ. Statistical significance was detected by t-test $p \leq 0.0001\left(^{(* * *)} ; p \leq 0.001\left(^{* * *}\right) ; p \leq 0.01\left(^{* *}\right)\right.$ and $p \leq 0.05$ $\left({ }^{*}\right)$.

role of YhbT has not yet been identified, but it contains the sterol carrier protein 2 domain (SCP2), suggesting a role in lipid and sterol transport ${ }^{67}$.

Signal transduction mechanism (T). Bacterial signal transduction networks regulate sensing and responses to environmental and intracellular parameters. In Pantoea sp. YR343, 235 proteins are predicted to be involved in signal transduction based on the COG category T (Table 5). Among these proteins, only 32 proteins were found to be differentially abundant in at least one fraction. In our data, we observed an abundance of OmpR family proteins ${ }^{68}$, including the phosphate regulon response regulator OmpR (PMI39_03347) in the $\triangle c r t B$ DRM fractions. OmpR, along with its histidine kinase partner EnvZ, are important for osmotic tolerance, virulence and motility in Acinetobacter baumanii ${ }^{69-71}$. In E. coli, OmpR and EnvZ regulate OmpF and OmpC proteins that are essential for responding to environmental signals.

\section{Conclusion}

The deletion of carotenoids in the $\Delta c r t B$ mutant leads not only to increased sensitivity to oxidative stress, but also to defects in IAA secretion, pellicle and biofilm formation, motility, and root colonization. In addition to the differences in lipid composition and membrane fluidity previously reported ${ }^{17}$, the loss of carotenoids also results in changes to the proteome of the $\Delta c r t B$ mutant compared to wildtype. We report a detailed proteome analysis comparing the wildtype and $\Delta c r t B$ mutant focusing on changes in membrane protein distribution and abundance. Consistent with the observed phenotypes in the mutant, we found that several classes of proteins belonging to membrane biogenesis, signal transduction, and cell motility were affected in the $\Delta c r t B$ mutant. The most dramatic changes to the proteome were observed in the DRM fraction, which is consistent with the idea that the DRM fraction represents membrane microdomains and the presence of cholesterol (in eukaryotes) or carotenoids and hopanoids (in prokaryotes) is vital to the organization of these domains ${ }^{72}$. In the absence of carotenoids, these microdomains may be unstable or have a change in membrane thickness which, in turn, 


\begin{tabular}{|c|c|c|c|c|c|c|c|}
\hline \multicolumn{8}{|c|}{ Cell motility } \\
\hline Locus tag & Gene name & TM/SP & $\begin{array}{c}\text { Whole } \\
\text { cell }\end{array}$ & $\begin{array}{c}\text { Membrane } \\
\text { pellet }\end{array}$ & DRM & DSM & Transcriptomics \\
\hline PMI39 04109 & Cellulose biosynthesis protein BcsQ & & & & & & \\
\hline PMI39_02605 & flagellar hook-associated protein 2 & & & & & & \\
\hline PMI39 02159 & flagellar hook-associated protein 2 & & & & & & \\
\hline PMI39 02182 & flagellar FliL protein & TM & & & & & \\
\hline PMI39_04337 & methyl-accepting chemotaxis protein & $\mathrm{TM}$ & & & & & \\
\hline PMI39_02618 & methyl-accepting chemotaxis protein & TM & & & & & \\
\hline PMI39 00776 & $\begin{array}{l}\text { methyl-accepting chemotaxis sensory } \\
\text { transducer with TarH sensor }\end{array}$ & $\mathrm{TM}$ & & & & & \\
\hline PMI39_00896 & flagellar protein FlgJ & & & & & & \\
\hline PMI39 03117 & $\begin{array}{l}\text { leader peptidase (prepilin peptidase) / } \\
\text { N-methyltransferase }\end{array}$ & $\mathrm{TM}$ & & & & & \\
\hline PMI39_02510 & major type 1 subunit fimbrin (pilin) & & & & & & \\
\hline PMI39 02163 & methyl-accepting chemotaxis protein & TM & & & & & \\
\hline PMI39 04071 & Methyl-accepting chemotaxis protein & $\mathrm{TM}$ & & & & & \\
\hline PMI39_02595 & $\begin{array}{l}\text { methyl-accepting chemotaxis protein- } \\
2, \text { aspartate sensor receptor }\end{array}$ & $\mathrm{TM}$ & & & & & \\
\hline PMI39_03890 & $\begin{array}{l}\text { methyl-accepting chemotaxis sensory } \\
\text { transducer with Cache sensor }\end{array}$ & $\mathrm{TM}$ & & & & & \\
\hline PMI39_02297 & $\begin{array}{l}\text { methyl-accepting chemotaxis sensory } \\
\text { transducer with Pas/Pac sensor }\end{array}$ & $\mathrm{TM}$ & & & & & \\
\hline PMI39 01148 & $\begin{array}{l}\text { methyl-accepting chemotaxis sensory } \\
\text { transducer with TarH sensor }\end{array}$ & $\mathrm{TM}$ & & & & & \\
\hline PMI39 02512 & outer membrane usher protein & SP & & & & & \\
\hline PMI39 02513 & $\begin{array}{l}\text { Pilin (type } 1 \text { fimbria component } \\
\text { protein) }\end{array}$ & SP & & & & & \\
\hline
\end{tabular}

Table 3. List of significantly differentially abundant proteins involved in cell motility. Protein list from JGI for each COG category was matched with the proteomics dataset and only proteins that were significantly different in at least in one fraction in the wildtype or $\Delta c r t B$ mutant are reported. TM/SP- proteins with transmembrane helices or signal peptide. Red: proteins that are significantly less abundant in the $\Delta c r t B$ mutant, green: proteins that are significantly more abundant in the $\Delta c r t B$ mutant, grey: non-significant proteins and white: proteins that are not detected.

affects protein insertion, stability, or recruitment. These data underscore the importance of bacterial membrane organization for cellular functions such as secretion, motility, and signaling.

\footnotetext{
Methods

Bacterial strains and growth conditions. Pantoea sp. YR343 and $\Delta c r t B$ cells were grown in Luria-Bertani broth (per $1 \mathrm{~L}, 10 \mathrm{~g}$ Bacto-tryptone, $10 \mathrm{~g} \mathrm{NaCl}, 5 \mathrm{~g}$ yeast extract) medium at $28^{\circ} \mathrm{C}$ with shaking to $\mathrm{OD}_{600}$ of 1 (stationary phase). The $\Delta c r t B$ mutant was constructed as described ${ }^{29}$.

Isolation of whole cell, crude membrane fraction, detergent resistant membrane and detergent sensitive membrane fractions of Pantoea sp. YR343 and $\Delta$ crt $B$ cells. To isolate different cell fractions, we used a modified version of the method described by Lopez ${ }^{18}$. Briefly, cells were grown in $500 \mathrm{~mL}$ of LB media overnight at $28^{\circ} \mathrm{C}$ with vigorous shaking. Cells were collected by centrifugation $(3000 \mathrm{~g}$ for $12 \mathrm{mins}$ ) and washed thrice in phosphate buffered saline (PBS). Cells were collected at this stage for whole cell proteomic analysis and stored at $-20^{\circ} \mathrm{C}$. Next, Buffer $\mathrm{H}$ (20 mM 4-(2-hydroxyethyl)-1-piperazineethanesulfonic acid (HEPES [pH 8], $20 \mathrm{mM} \mathrm{NaCl}, 1 \mathrm{mM}$ dithiothreitol [DTT], $1 \mathrm{mM}$ phenylmethylsulfonyl fluoride [PMSF]), lysozyme $(1 \mathrm{mg} / \mathrm{mL})$, PMSF $(100 \mu \mathrm{M})$, and DNase I was added to the washed cells. Cells were disrupted using French press followed by a short centrifugation to eliminate cell debris. The membrane fraction was precipitated by ultracentrifugation $\left(100,000 \times g\right.$ for $1 \mathrm{~h}$ at $\left.4^{\circ} \mathrm{C}\right)$. The resulting cell pellet was resuspended in Buffer $\mathrm{H}$ with $10 \%$ glycerol. At this stage, a fraction of the membrane pellet was collected.
} 


\begin{tabular}{|c|c|c|c|c|c|c|c|}
\hline \multicolumn{8}{|c|}{ Lipid transport and metabolism } \\
\hline Locus tag & Gene Name & TM/SP & $\begin{array}{c}\text { Whole } \\
\text { cells }\end{array}$ & \begin{tabular}{|c|}
$\begin{array}{c}\text { Membrane } \\
\text { pellet }\end{array}$ \\
\end{tabular} & DRM & DSM & Transcriptomics \\
\hline PMI39_00881 & $\begin{array}{l}\text { 3-oxoacyl-[acyl-carrier-protein] } \\
\text { synthase II }\end{array}$ & & & & & & \\
\hline PMI39_00789 & $\begin{array}{l}\text { NAD(P)-dependent dehydrogenase, } \\
\text { short-chain alcohol dehydrogenase } \\
\text { family }\end{array}$ & & & & & & \\
\hline PMI39 02975 & 3-hydroxyisobutyrate dehydrogenase & & & & & & \\
\hline PMI39_02976 & $\begin{array}{l}\text { Lysophospholipase, alpha-beta } \\
\text { hydrolase superfamily }\end{array}$ & & & & & & \\
\hline PMI39_01503 & $\begin{array}{l}\text { Predicted lipid carrier protein YhbT, } \\
\text { contains SCP2 domain }\end{array}$ & & & & & & \\
\hline PMI39_02402 & acetyl-CoA acyltransferase & & & & & & \\
\hline PMI39 03583 & $\begin{array}{l}\text { 4-hydroxy-3-methylbut-2-en-1-yl } \\
\text { diphosphate synthase }\end{array}$ & & & & & & \\
\hline PMI39_04767 & $\begin{array}{l}\text { cyclopropane-fatty-acyl-phospholipid } \\
\text { synthase }\end{array}$ & & & & & & \\
\hline PMI39_00695 & putative cardiolipin synthase & & & & & & \\
\hline PMI39 03673 & $\begin{array}{l}\text { acetyl-CoA carboxylase } \\
\text { carboxyltransferase subunit alpha }\end{array}$ & & & & & & \\
\hline PMI39 02890 & choline dehydrogenase & & & & & & \\
\hline PMI39 03843 & outer membrane lipase/esterase & $\mathrm{TM}+\mathrm{SP}$ & & & & & \\
\hline PMI39_00318 & choline dehydrogenase & & & & & & \\
\hline PMI39_01261 & $\begin{array}{l}\text { Lysophospholipase, alpha-beta } \\
\text { hydrolase superfamily }\end{array}$ & & & & & & \\
\hline PMI39 04227 & $\begin{array}{l}\text { NAD(P)-dependent dehydrogenase, } \\
\text { short-chain alcohol dehydrogenase } \\
\text { family }\end{array}$ & & & & & & \\
\hline PMI39_04693 & $\begin{array}{l}\text { NAD(P)-dependent dehydrogenase, } \\
\text { short-chain alcohol dehydrogenase } \\
\text { family }\end{array}$ & & & & & & \\
\hline PMI39 04916 & $\begin{array}{l}\text { Lysophospholipase, alpha-beta } \\
\text { hydrolase superfamily }\end{array}$ & TM & & & & & \\
\hline PMI39_00023 & acetyl-CoA acyltransferase & & & & & & \\
\hline PMI39 02734 & cardiolipin synthase & TM & & & & & \\
\hline PMI39_01258 & $\begin{array}{l}\text { Phosphatidylglycerophosphate } \\
\text { synthase }\end{array}$ & TM & & & & & \\
\hline PMI39_02871 & acyl-CoA thioester hydrolase & & & & & & \\
\hline PMI39 04133 & $\begin{array}{l}\text { NAD(P)-dependent dehydrogenase, } \\
\text { short-chain alcohol dehydrogenase } \\
\text { family }\end{array}$ & & & & & & \\
\hline PMI39 04906 & L-fucose dehydrogenase & & & & & & \\
\hline PMI39_02456 & $\begin{array}{l}\begin{array}{l}\text { L-lactate dehydrogenase } \\
\text { (cytochrome) }\end{array} \\
\end{array}$ & & & & & & \\
\hline PMI39_03968 & acyl-CoA dehydrogenase & TM & & & & & \\
\hline PMI39 04547 & diacylglycerol kinase (ATP) & TM & & & & & \\
\hline
\end{tabular}

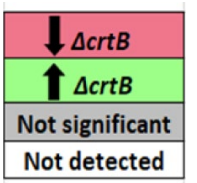

Table 4. List of significantly differentially abundant proteins involved in lipid transport and metabolism. Protein list from JGI for each COG category was matched with the proteomics dataset and only proteins that were significantly different in at least in one fraction in the wildtype or $\Delta c r t B$ mutant are reported. TM/SPproteins with transmembrane helices or signal peptide. Red: proteins that are significantly less abundant in the $\Delta c r t B$ mutant, green: proteins that are significantly more abundant in the $\Delta c r t B$ mutant, grey: non-significant proteins and white: proteins that are not detected. 


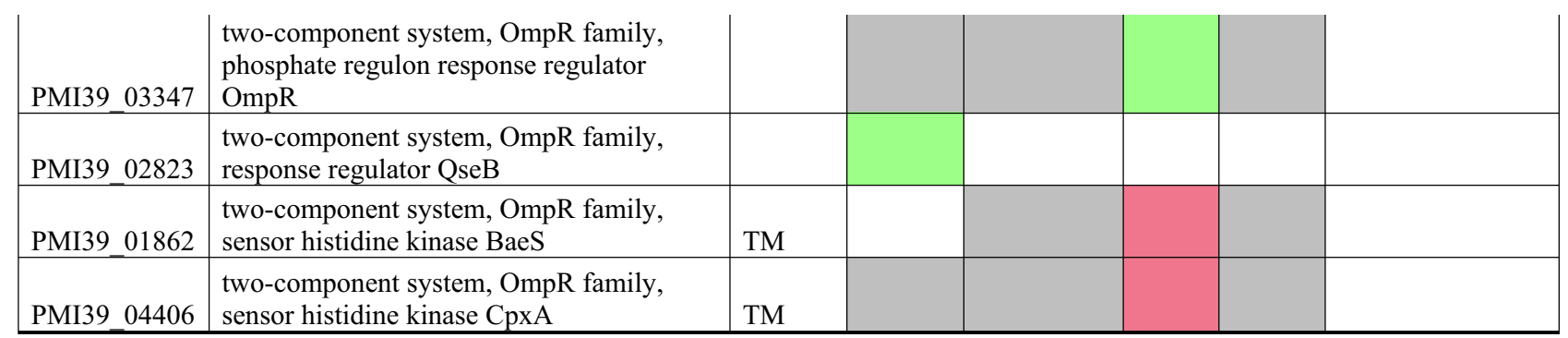

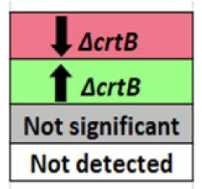

(continued)

To isolate DRM and DSM fractions, the membrane pellet was incubated for $30 \mathrm{~min}$ at $4{ }^{\circ} \mathrm{C}$ with lysis and separation buffer (CelLytic MEM protein extraction kit from Sigma Aldrich). After incubation, the membrane pellet was mixed $1: 1$ with $80 \%$ sucrose and carefully overlaid with $20 \%$ sucrose. Using a swinging bucket rotor, separation was carried out at $100,000 \times g$ at $4{ }^{\circ} \mathrm{C}$ for $16 \mathrm{~h}$. The DRM and DSM fractions were collected and stored at $-20^{\circ} \mathrm{C}$ for proteomic analysis.

Protein extraction and digestion. Cell pellets were suspended in sodium dodecyl sulfate (SDS) lysis buffer ( $2 \%$ in $100 \mathrm{mM}$ of $\mathrm{NH}_{4} \mathrm{HCO}_{3}, 10 \mathrm{mM}$ DTT). Samples were physically disrupted by bead beating $(0.15 \mathrm{~mm})$ at $8,000 \mathrm{rpm}$ for $5 \mathrm{~min}$. Crude lysates were boiled for $5 \mathrm{~min}$ at $90^{\circ} \mathrm{C}$. Cysteines were blocked to avoid disulfide bridge reformation by adjusting each sample to $30 \mathrm{mM}$ IAA and incubating in the dark for $15 \mathrm{~min}$ at room temperature. Proteins were precipitated using a chloroform $/ \mathrm{methanol} /$ water extraction. Dried protein pellets were resuspended in $2 \%$ sodium deoxycholate (SDC) $\left(100 \mathrm{mM} \mathrm{NH}_{4} \mathrm{HCO}_{3}\right)$ and protein amounts were estimated by performing a BCA assay (Pierce Biotechnology). In general, membrane fractions from the mutant showed a reduced protein concentration compared to wild type (MP: $3.7 \mathrm{mg} / \mathrm{mL}$ (wt) and $2.8 \mathrm{mg} / \mathrm{mL}(\Delta c r t B)$; DSM: $858 \mu \mathrm{g} / \mathrm{mL}$ (wt) and $845 \mu \mathrm{g} / \mathrm{mL}(\Delta c r t B$ ); DRM: $165 \mu \mathrm{g} / \mathrm{mL}$ (wt) and $138 \mu \mathrm{g} / \mathrm{mL}(\Delta c r t B)$ ). For each sample, an aliquot of approximately $500 \mu \mathrm{g}$ of protein was digested via two aliquots of sequencing-grade trypsin (Promega, 1:75 [w:w]) at two different sample dilutions, (overnight) followed by incubating $3 \mathrm{~h}$ at $37^{\circ} \mathrm{C}$. The peptide mixture was adjusted to $0.5 \%$ formaldehyde (FA) to precipitate SDC. Hydrated ethyl acetate was added to each sample at a 1:1 [v:v] ratio three times to effectively remove SDC. Samples were then placed in a SpeedVac Concentrator (Thermo Fischer Scientific) to remove ethyl acetate and further concentrate the sample. The peptideenriched flow through was quantified using the BCA assay, desalted on RP-C18 stage tips (Pierce Biotechnology) and then stored at $-80^{\circ} \mathrm{C}$ prior to LC-MS/MS analysis.

LC-MS/MS. All samples were analyzed on a Q Exactive Plus mass spectrometer (Thermo Fisher Scientific) coupled with a Proxeon EASY-nLC 1200 liquid chromatography (LC) pump (Thermo Fisher Scientific) as previously described ${ }^{73}$. In brief, peptide mixtures were separated on a $75 \mu \mathrm{m}$ inner diameter microcapillary column packed with $30 \mathrm{~cm}$ of Kinetex $\mathrm{C} 18$ resin $(1.7 \mu \mathrm{m}, 100 \AA$, Phenomenex $)$. For each peptide mixture, a $2 \mu \mathrm{g}$ aliquot was loaded in buffer A ( $0.1 \%$ formic acid, $2 \%$ acetonitrile) and eluted with a linear 150 min gradient of 2-20\% of buffer B ( $0.1 \%$ formic acid, $80 \%$ acetonitrile), followed by an increase in buffer B to $30 \%$ for $10 \mathrm{~min}$, another increase to $50 \%$ buffer for $10 \mathrm{~min}$ and concluding with a $10 \mathrm{~min}$ wash at $98 \%$ buffer $\mathrm{A}$. The flow rate was kept at $200 \mathrm{~nL} / \mathrm{min}$. Mass spectra data was acquired with the Thermo Xcalibur software version 2.2, and a topN method where $\mathrm{N}$ could be up to 15 was employed for data-dependent acquisition ${ }^{73}$.

Peptide identification and protein inference. MS raw data files were searched against the Pantoea sp. YR343 FASTA database to which common contaminate proteins had been added. A decoy database, consisting of the reversed sequences of the target database, was appended to discern the false-discovery rate (FDR) at the spectral level. For standard database searching, the peptide fragmentation spectra (MS/MS) were analyzed by the Crux pipeline v3.0 $0^{74}$. The MS/MS were searched using the Tide algorithm ${ }^{75}$ and was configured to derive fully-tryptic peptides using default settings except for the following parameters: allowed clip nterm-methionine, a precursor mass tolerance of 10 parts per million ( $\mathrm{ppm}$ ), a static modification on cysteines (iodoacetamide; +57.0214 Da), and dynamic modifications on methionine (oxidation; 15.9949). The results were processed by Percolator ${ }^{76}$ to estimate $q$ values. Peptide spectrum matches (PSMs) and peptides were considered identified at a $q$ value $<0.01$. Across the entire experimental dataset, proteins were required to have at least 2 distinct peptide sequences and 2 minimum spectra per protein.

Protein quantification. For label-free quantification, MS1-level precursor intensities were derived from $\mathrm{MOFF}^{77}$ using the following parameters: $10 \mathrm{ppm}$ mass tolerance, retention time window for extracted ion chro- 


\begin{tabular}{|c|c|c|c|c|c|c|c|}
\hline \multicolumn{8}{|c|}{ Signal transduction mechanisms } \\
\hline Locus Tag & Gene name & TM/SP & $\begin{array}{c}\text { Whole } \\
\text { cell }\end{array}$ & $\begin{array}{c}\text { Membrane } \\
\text { pellet }\end{array}$ & DRM & DSM & Transcriptomics \\
\hline PMI39_02445 & $\begin{array}{l}\text { amino acid } \mathrm{ABC} \text { transporter substrate- } \\
\text { binding protein, PAAT family }\end{array}$ & SP & & & & & \\
\hline PMI39 00574 & $\begin{array}{l}\text { arginine transport system substrate-binding } \\
\text { protein }\end{array}$ & SP & & & & & \\
\hline PMI39 02695 & carbon starvation protein & TM & & & & & \\
\hline PMI39_00272 & cell filamentation protein & & & & & & \\
\hline PMI39_00276 & $\begin{array}{l}\text { CRP/FNR family transcriptional regulator, } \\
\text { cyclic AMP receptor protein }\end{array}$ & & & & & & \\
\hline PMI39 02334 & $\begin{array}{l}\text { diguanylate cyclase (GGDEF) domain- } \\
\text { containing protein }\end{array}$ & $\mathrm{TM}$ & & & & & \\
\hline PMI39 00427 & $\begin{array}{l}\text { DNA-binding response regulator, OmpR } \\
\text { family, contains REC and winged-helix } \\
\text { (wHTH) domain }\end{array}$ & & & & & & \\
\hline PMI39_03053 & $\begin{array}{l}\text { EAL domain, c-di-GMP-specific } \\
\text { phosphodiesterase class I (or its } \\
\text { enzymatically inactive variant) }\end{array}$ & & & & & & \\
\hline PMI39_02173 & $\begin{array}{l}\text { EAL domain, c-di-GMP-specific } \\
\text { phosphodiesterase class I (or its } \\
\text { enzymatically inactive variant) }\end{array}$ & & & & & & \\
\hline PMI39_00644 & hypothetical protein & & & & & & \\
\hline PMI39 04647 & $\begin{array}{l}\text { lysine/arginine/ornithine transport system } \\
\text { substrate-binding protein }\end{array}$ & SP & & & & & \\
\hline PMI39_04337 & methyl-accepting chemotaxis protein & $\mathrm{TM}$ & & & & & \\
\hline PMI39 02618 & methyl-accepting chemotaxis protein & TM & & & & & \\
\hline PMI39_02163 & methyl-accepting chemotaxis protein & TM & & & & & \\
\hline PMI39_02297 & $\begin{array}{l}\text { methyl-accepting chemotaxis sensory } \\
\text { transducer with Pas/Pac sensor }\end{array}$ & TM & & & & & \\
\hline PMI39_00776 & $\begin{array}{l}\text { methyl-accepting chemotaxis sensory } \\
\text { transducer with TarH sensor }\end{array}$ & $\mathrm{TM}$ & & & & & \\
\hline PMI39 01148 & $\begin{array}{l}\text { methyl-accepting chemotaxis sensory } \\
\text { transducer with TarH sensor }\end{array}$ & $\mathrm{TM}$ & & & & & \\
\hline PMI39_04597 & multi-sensor hybrid histidine kinase & TM & & & & & \\
\hline PMI39_02678 & $\begin{array}{l}\text { phage shock protein } \mathrm{C}(\mathrm{PspC}) \text { family } \\
\text { protein }\end{array}$ & TM & & & & & \\
\hline PMI39_02138 & $\begin{array}{l}\text { phosphate starvation-inducible protein } \\
\text { PhoH }\end{array}$ & & & & & & \\
\hline PMI39_04090 & $\begin{array}{l}\text { polar amino acid transport system } \\
\text { substrate-binding protein }\end{array}$ & SP & & & & & \\
\hline PMI39_04190 & $\begin{array}{l}\text { SOS-response transcriptional repressor } \\
\text { LexA (RecA-mediated autopeptidase) }\end{array}$ & & & & & & \\
\hline PMI39_01240 & tellurium resistance protein TerZ & & & & & & \\
\hline PMI39_03635 & $\begin{array}{l}\text { two component transcriptional regulator, } \\
\text { LuxR family }\end{array}$ & & & & & & \\
\hline PMI39_02508 & $\begin{array}{l}\text { two component transcriptional regulator, } \\
\text { LuxR family }\end{array}$ & & & & & & \\
\hline PMI39_04141 & $\begin{array}{l}\text { two component transcriptional regulator, } \\
\text { LuxR family }\end{array}$ & & & & & & \\
\hline PMI39_02514 & $\begin{array}{l}\text { two-component system, NarL family, } \\
\text { response regulator EvgA }\end{array}$ & & & & & & \\
\hline
\end{tabular}

Table 5. List of significantly differentially abundant proteins involved in signal transduction mechanisms. Protein list from JGI for each COG category was matched with the proteomics dataset and only proteins that were significantly different in at least in one fraction in the wildtype or $\Delta c r t B$ mutant are reported. TM/SPproteins with transmembrane helices or signal peptide. Red: proteins that are significantly less abundant in the $\Delta c r t B$ mutant, green: proteins that are significantly more abundant in the $\Delta c r t B$ mutant, grey: non-significant proteins and white: proteins that are not detected. 
matogram was $3 \mathrm{~min}$, time window to get the apex for MS/MS precursor was $30 \mathrm{~s}$. Protein intensity-based values, which were calculated by summing together quantified peptides, normalized by dividing by protein length and then LOESS and median central tendency procedures were performed on $\log 2$-transformed data using the freely available software Perseus (. Missing values were replaced by random numbers drawn from a normal distribution (width $=0.3$ and downshift $=2.8$ ).

Statistical analysis for differential abundances. For this study, we performed ANOVA with post-hoc Tukey's test to identify differential protein abundances across the wildtype Pantoea sp. YR343 dataset comparisons or $\Delta c r t B$ mutant dataset comparisons and protein abundances were considered to have a significant change in abundance for $p$ values $<0.05$ and at least one absolute value of $\log 2$ fold-change differences $>1$. To identify differential protein abundances between wildtype and $\Delta c r t B$ fractions, we performed a Student's t-test for the pairwise comparisons. A protein was categorized as having a significant abundance difference if it passed a significance threshold requiring a $p$ value $<0.05$ and absolute value of $\log 2$ fold-change difference $>1$. Hierarchical clustering (one-way; Fast Ward method) was performed to identify differential abundance patterns.

Gene ontology enrichment. Gene ontology (GO) term annotation was performed using Blast $2 \mathrm{GO}^{38}$ with a blastp E-value hit filter of $1 \times 10^{-5}$, an annotation cutoff value of 55 and a GO weight of 5 . Using the Cytoscape ${ }^{79}$ plugin ClueGO ${ }^{80}$, observed GO biological processes were subjected to the right-sided hypergeometric enrichment test at medium network specificity selection and p-value correction was performed using the Holm-Bonferroni step-down method ${ }^{81}$. For each cluster, we required a minimum of 3 and a maximum of 8 selected GO tree levels, and each cluster was set to include a minimum of 3- $4 \%$ of genes associated with each term. The GO terms at adjusted $\mathrm{p}<0.05$ were considered significantly enriched.

RNA extraction, sequencing and analysis. Wild type and $\Delta c r t B$ cells were grown to stationary phase $\left(\mathrm{OD}_{600}=1\right)$. RNA was extracted using RNeasy mini kit (QIAGEN, Valencia, CA) following manufacturer's instructions and quantified using Nanodrop (Thermo Scientific). Sequencing was carried out by GENEWIZ Next Generation Sequencing Services. Transcript analysis was carried out using KBase ${ }^{50}$ (https://kbase.us/). KBase and its tools were used to generate the sample set, align and assemble reads to the genome, and identify differentially abundant genes between wild type and $\Delta c r t B$.

Motility assays. To compare the swimming motility function of Pantoea sp. YR343 and $\Delta c r t B$ cells, cells were grown overnight with shaking $(250 \mathrm{rpm})$ in $\mathrm{LB}$ medium at $28^{\circ} \mathrm{C}$. Swimming motility was examined on $\mathrm{LB}$ containing $0.3 \% \mathrm{w} / \mathrm{v}$ agar. A $5 \mu \mathrm{L}$ aliquot of cells were inoculated in the center of the plate and incubated at $28^{\circ} \mathrm{C}$ for $18 \mathrm{~h}$. Live cell imaging of bacterial motility was measured using a Nikon Eclipse Ti-U inverted microscope. Cells from motility plates were inoculated in R2A media overnight at $28^{\circ} \mathrm{C}$ with shaking $(250 \mathrm{rpm})$. Next day, cells were reinoculated in R2A media and grown to an $\mathrm{OD}_{600}$ of 0.5 . A $20 \mu \mathrm{L}$ aliquot of cells were placed on a coverslip and $10 \mathrm{~s}$ videos were captured using NIS-Elements imaging software. Trajectories and velocities (pixels/frame) of Pantoea sp. YR343 and $\Delta c r t B$ cells were calculated with the "TrackMate" plugin (https://imagej. net/TrackMate).

Flagella staining. Flagella staining was carried out using a protocol adapted from Turner et al. ${ }^{82}$. Briefly, Pantoea sp. YR343 and $\triangle c r t B$ cells from swimming plates were inoculated overnight in R2A medium at $28^{\circ} \mathrm{C}$ with shaking (250 rpm). Next day, cells were diluted 1:10 in fresh R2A medium and grown to $\mathrm{OD}_{600}$ of 0.5 . Motility of the culture was confirmed using a confocal microscope. Cells were collected by centrifugation $\left(2000^{\star} \mathrm{g}\right.$, $3 \mathrm{~min}$ ) and washed three times in buffer $\left(0.01 \mathrm{M} \mathrm{KPO}_{4}, 0.067 \mathrm{M} \mathrm{NaCl}, 10^{-4} \mathrm{M}\right.$ (Ethylenediaminetetraacetic acid (EDTA) [pH 7.0]). Alexa Fluor 594 carboxylic acid succinimidyl ester (ThermoFisher Scientific) was added to the concentrated bacterial suspension and incubated in the dark for $1 \mathrm{~h}$. Cells were then washed three times with buffer containing Brij $35\left(10^{-4} \%\right)$ and $0.4 \%$ glucose. Concentrated cells were then placed on an agarose pad $(1 \%$ agarose in phosphate buffered saline) and imaged using a Zeiss LSM 710 confocal microscope. Flagellar length of 30 wildtype and $\Delta c r t B$ cells were measured using ImageJ. The data are represented as the mean flagellar length in $\mu \mathrm{m} \pm \mathrm{SE}$ calculated using unpaired t-test.

\section{Data availability}

All proteomics mass spectrometry data collected in this study was deposited at the ProteomeXchange Consortium via the MASSIVE repository under the project identifier MSV000085068.

Received: 12 May 2020; Accepted: 5 August 2020

Published online: 11 September 2020

\section{References}

1. Gennis, R. B. Biomembranes: Molecular Structure and Function (Springer, Berlin, 2013).

2. Sunshine, H. \& Iruela-Arispe, M. L. Membrane lipids and cell signaling. Curr. Opin. Lipidol. 28, 408-413. https://doi.org/10.1097/ mol.0000000000000443 (2017).

3. Schlegel, S. et al. Revolutionizing membrane protein overexpression in bacteria. Microb. Biotechnol. 3, 403-411. https://doi.org/ 10.1111/j.1751-7915.2009.00148.x (2010).

4. Wallin, E. \& von Heijne, G. Genome-wide analysis of integral membrane proteins from eubacterial, archaean, and eukaryotic organisms. Protein Sci. 7, 1029-1038. https://doi.org/10.1002/pro.5560070420 (1998).

5. Dirienzo, J. M., Nakamura, K. \& Inouye, M. The outer membrane proteins of Gram-negative bacteria: biosynthesis, assembly, and functions. Annu. Rev. Biochem. 47, 481-532 (1978). 
6. Koebnik, R., Locher, K. P. \& Van Gelder, P. Structure and function of bacterial outer membrane proteins: barrels in a nutshell. Mol. Microbiol. 37, 239-253 (2000).

7. Koronakis, V., Sharff, A., Koronakis, E., Luisi, B. \& Hughes, C. Crystal structure of the bacterial membrane protein TolC central to multidrug efflux and protein export. Nature 405, 914 (2000).

8. Vershinin, A. Biological functions of carotenoids-diversity and evolution. BioFactors 10, 99-104 (1999).

9. Olson, J. A. \& Krinsky, N. I. Introduction: the colorful, fascinating world of the carotenoids: important physiologic modulators. FASEB J. 9, 1547-1550 (1995).

10. Kirti, K., Amita, S., Priti, S., Mukesh Kumar, A. \& Jyoti, S. Colorful world of microbes: carotenoids and their applications. Adv. Biol. https://doi.org/10.1155/2014/837891 (2014).

11. Boulay, C., Abasova, L., Six, C., Vass, I. \& Kirilovsky, D. Occurrence and function of the orange carotenoid protein in photoprotective mechanisms in various cyanobacteria. Biochim. Biophys. Acta (BBA) Bioenerg. 1777, 1344-1354. https://doi.org/10.1016/j. bbabio.2008.07.002 (2008)

12. Hashimoto, H., Uragami, C. \& Cogdell, R. J. Carotenoids and photosynthesis. Subcell Biochem. 79, 111-139. https://doi.org/10. 1007/978-3-319-39126-7_4 (2016).

13. Mishra, N. N. et al. Carotenoid-related alteration of cell membrane fluidity impacts Staphylococcus aureus susceptibility to host defense peptides. Antimicrob. Agents Chemother. 55, 526-531. https://doi.org/10.1128/aac.00680-10 (2011).

14. Havaux, M. Carotenoids as membrane stabilizer in chloroplasts. Trends Plant Sci. 3, 147-151 (1998).

15. Gabrielska, J. \& Gruszecki, W. I. Zeaxanthin (dihydroxy- $\beta$-carotene) but not $\beta$-carotene rigidifies lipid membranes: a $1 \mathrm{H}$-NMR study of carotenoid-egg phosphatidylcholine liposomes. Biochim. Biophys. Acta (BBA) Biomembr. 1285, 167-174 (1996).

16. Johnson, Q. R., Mostofian, B., Gomez, G. F., Smith, J. C. \& Cheng, X. Effects of carotenoids on lipid bilayers. Phys. Chem. Chem. Phys. 20, 3795-3804 (2018).

17. Vijaya Kumar, S. et al. Loss of carotenoids from membranes of Pantoea sp. YR343 results in altered lipid composition and changes in membrane biophysical properties. Biochim. Biophys. Acta Biomembr. 1861, 1338-1345. https://doi.org/10.1016/j.bbamem.2019. 05.009 (2019).

18. Bramkamp, M. \& Lopez, D. Exploring the existence of lipid rafts in bacteria. Microbiol. Mol. Biol. Rev. 79, 81-100. https://doi.org/ 10.1128/mmbr.00036-14 (2015).

19. Lopez, D. \& Koch, G. Exploring functional membrane microdomains in bacteria: an overview. Curr. Opin. Microbiol. 36, 76-84 (2017).

20. López, D. \& Kolter, R. Functional microdomains in bacterial membranes. Gene Dev. 24, 1893-1902 (2010).

21. Bach, J. N. \& Bramkamp, M. Flotillins functionally organize the bacterial membrane. Mol. Microbiol. 88, 1205-1217. https://doi. org $/ 10.1111 / \mathrm{mmi} .12252(2013)$.

22. Dermine, J. F. et al. Flotillin-1-enriched lipid raft domains accumulate on maturing phagosomes. J. Biol. Chem. 276, 18507-18512. https://doi.org/10.1074/jbc.M101113200 (2001).

23. Solomon, S. et al. The lipid raft microdomain-associated protein reggie-1/flotillin-2 is expressed in human B cells and localized at the plasma membrane and centrosome in PBMCs. Immunobiology 205, 108-119. https://doi.org/10.1078/0171-2985-00114 (2002).

24. Lopez, D. \& Kolter, R. Functional microdomains in bacterial membranes. Gene Dev. 24, 1893-1902. https://doi.org/10.1101/gad. 1945010 (2010).

25. Somani, V. K., Aggarwal, S., Singh, D., Prasad, T. \& Bhatnagar, R. Identification of novel raft marker protein, FlotP in Bacillus anthracis. Front. Microbiol. 7, 169 (2016).

26. Bach, J. N. \& Bramkamp, M. Dissecting the molecular properties of prokaryotic flotillins. PLoS ONE 10, e0116750 (2015).

27. Schneider, J., Mielich-Süss, B., Böhme, R. \& Lopez, D. In vivo characterization of the scaffold activity of flotillin on the membrane kinase KinC of Bacillus subtilis. Microbiology 161, 1871-1887 (2015).

28. Simons, K. \& Sampaio, J. L. Membrane organization and lipid rafts. Csh. Perspect. Biol. https://doi.org/10.1101/cshperspect.a0046 97 (2011).

29. Bible, A. N. et al. A carotenoid-deficient mutant in Pantoea sp. YR343, a bacteria isolated from the rhizosphere of Populus deltoides, is defective in root colonization. Front. Microbiol. 7, 491. https://doi.org/10.3389/fmicb.2016.00491 (2016).

30. Dubois, L., Ronquist, K. K., Ek, B., Ronquist, G. \& Larsson, A. Proteomic profiling of detergent resistant membranes (lipid rafts) of prostasomes. Mol. Cell Proteomics 14,3015-3022. https://doi.org/10.1074/mcp.M114.047530 (2015).

31. Andersen, O. S., Roger, E. \& Koeppe, I. Bilayer thickness and membrane protein function: an energetic perspective. Annu. Rev. Biophys. Biomol. Struct. 36, 107-130. https://doi.org/10.1146/annurev.biophys.36.040306.132643 (2007).

32. Cerezo, J., Zúñiga, J., Bastida, A., Requena, A. \& Ceron-Carrasco, J. P. Conformational changes of $\beta$-carotene and zeaxanthin immersed in a model membrane through atomistic molecular dynamics simulations. Phys. Chem. Chem. Phys. 15, 6527-6538 (2013).

33. Li, L. B., Vorobyov, I. \& Allen, T. W. The role of membrane thickness in charged protein-lipid interactions. Biochim. Biophys. Acta (BBA) Biomembr. 1818, 135-145 (2012).

34. Andersen, O. S. \& Koeppe, R. E. II. Bilayer thickness and membrane protein function: an energetic perspective. Annu. Rev. Biophys. Biomol. Struct. 36, 107-130. https://doi.org/10.1146/annurev.biophys.36.040306.132643 (2007).

35. Tan, S., Tan, H. T. \& Chung, M. C. Membrane proteins and membrane proteomics. Proteomics 8, 3924-3932 (2008).

36. Matkó, J. \& Szöllősi, J. Membrane Microdomain Signaling 15-46 (Springer, Berlin , 2005).

37. Tatusov, R. L., Galperin, M. Y., Natale, D. A. \& Koonin, E. V. The COG database: a tool for genome-scale analysis of protein functions and evolution. Nucleic Acids Res. 28, 33-36 (2000).

38. Conesa, A. et al. Blast2GO: a universal tool for annotation, visualization and analysis in functional genomics research. Bioinformatics 21, 3674-3676. https://doi.org/10.1093/bioinformatics/bti610 (2005).

39. Dalebroux, Z. D. Cues from the membrane: bacterial glycerophospholipids. J. Bacteriol. https://doi.org/10.1128/jb.00136-17 (2017).

40. Istivan, T. S. \& Coloe, P. J. Phospholipase A in Gram-negative bacteria and its role in pathogenesis. Microbiology 152, $1263-1274$. https://doi.org/10.1099/mic.0.28609-0 (2006).

41. Hinderhofer, M. et al. Evolution of prokaryotic SPFH proteins. BMC Evol. Biol. 9, 10. https://doi.org/10.1186/1471-2148-9-10 (2009).

42. Rivera-Milla, E., Stuermer, C. A. \& Malaga-Trillo, E. Ancient origin of reggie (flotillin), reggie-like, and other lipid-raft proteins: convergent evolution of the SPFH domain. Cell Mol. Life Sci. 63, 343-357. https://doi.org/10.1007/s00018-005-5434-3 (2006).

43. Sanyal, S. \& Menon, A. K. Flipping lipids: why an' what's the reason for?. ACS Chem. Biol. 4, 895-909. https://doi.org/10.1021/ cb900163d (2009).

44. TouzÉ, T. \& Mengin-Lecreulx, D. Undecaprenyl phosphate synthesis. EcoSal Plus https://doi.org/10.1128/ecosalplus.4.7.1.7 (2008).

45. Herrera, C. M., Koutsoudis, M. D., Wang, X. \& von Bodman, S. B. Pantoea stewartii subsp. stewartii exhibits surface motility, which is a critical aspect of Stewart's wilt disease development on maize. Mol. Plant Microbe Interact. 21, 1359-1370. https://doi.org/10. 1094/mpmi-21-10-1359 (2008).

46. Hartley, M. D. \& Imperiali, B. At the membrane frontier: a prospectus on the remarkable evolutionary conservation of polyprenols and polyprenyl-phosphates. Arch. Biochem. Biophys. 517, 83-97. https://doi.org/10.1016/j.abb.2011.10.018 (2012).

47. de Ropp, J. S. \& Troy, F. A. 2H NMR investigation of the organization and dynamics of polyisoprenols in membranes. J. Biol. Chem. 260, 15669-15674 (1985). 
48. Janas, T., Chojnacki, T., Swiezewska, E. \& Janas, T. The effect of undecaprenol on bilayer lipid membranes. Acta Biochim. Pol. 41, 351-358 (1994).

49. Noinaj, N., Guillier, M., Barnard, T. J. \& Buchanan, S. K. TonB-dependent transporters: regulation, structure, and function. Annu. Rev. Microbiol. 64, 43-60. https://doi.org/10.1146/annurev.micro.112408.134247 (2010).

50. Arkin, A. P. et al. KBase: The United States Department of Energy Systems Biology Knowledgebase. Nat. Biotechnol. 36, 566 (2018).

51. Dolph, P. J., Majerczak, D. R. \& Coplin, D. L. Characterization of a gene cluster for exopolysaccharide biosynthesis and virulence in Erwinia stewartii. J. Bacteriol. 170, 865-871 (1988).

52. Geider, K. Exopolysaccharides of Erwinia amylovora: structure, biosynthesis, regulation, role in pathogenicity of. Fire Blight: The Disease and Its Causative Agent, Erwinia amylovora, 117 (2000).

53. Han, L. et al. Structure of the BAM complex and its implications for biogenesis of outer-membrane proteins. Nat. Struct. Mol. Biol. 23, 192 (2016).

54. Rigel, N. W. \& Silhavy, T. J. Making a beta-barrel: assembly of outer membrane proteins in Gram-negative bacteria. Curr. Opin. Microbiol. 15, 189-193. https://doi.org/10.1016/j.mib.2011.12.007 (2012).

55. Zückert, W. R. Secretion of bacterial lipoproteins: through the cytoplasmic membrane, the periplasm and beyond. Biochim. Biophys. Acta 1843, 1509-1516. https://doi.org/10.1016/j.bbamcr.2014.04.022 (2014).

56. Noinaj, N., Fairman, J. W. \& Buchanan, S. K. The crystal structure of bamb suggests interactions with BamA and its role within the BAM complex. J. Mol. Biol. 407, 248-260. https://doi.org/10.1016/j.jmb.2011.01.042 (2011).

57. Malinverni, J. C. \& Silhavy, T. J. Assembly of outer membrane $\beta$-barrel proteins: the Bam complex. EcoSal Plus. https://doi.org/10. 1128/ecosalplus.4.3.8 (2011).

58. Gunasinghe, S. D. et al. The WD40 protein BamB mediates coupling of BAM complexes into assembly precincts in the bacterial outer membrane. Cell Rep. 23, 2782-2794. https://doi.org/10.1016/j.celrep.2018.04.093 (2018).

59. Hussain, S. \& Bernstein, H. D. The Bam complex catalyzes efficient insertion of bacterial outer membrane proteins into membrane vesicles of variable lipid composition. J. Biol. Chem. 293, 2959-2973. https://doi.org/10.1074/jbc.RA117.000349 (2018).

60. Schiffrin, B. et al. Skp is a multivalent chaperone of outer membrane proteins. Nat. Struct. Mol. Biol. 23, 786-793. https://doi.org/ 10.1038/nsmb.3266 (2016).

61. Bardy, S. L., Ng, S. Y. M. \& Jarrell, K. F. Prokaryotic motility structures. Microbiology 149, 295-304. https://doi.org/10.1099/mic.0. 25948-0 (2003).

62. Partridge, J. D., Nieto, V. \& Harshey, R. M. A new player at the flagellar motor: FliL controls both motor output and bias. mBio https://doi.org/10.1128/mBio.02367-14 (2015)

63. Zhu, S., Kumar, A., Kojima, S. \& Homma, M. FliL associates with the stator to support torque generation of the sodium-driven polar flagellar motor of Vibrio. Mol. Microbiol. 98, 101-110 (2015).

64. Kehry, M. \& Dahlquist, F. The methyl-accepting chemotaxis proteins of Escherichia coli. Identification of the multiple methylation sites on methyl-accepting chemotaxis protein I. J. Biol. Chem. 257, 10378-10386 (1982).

65. Wood, J. M. et al. Osmosensing and osmoregulatory compatible solute accumulation by bacteria. Comp. Biochem. Physiol. A Mol. Integr. Physiol. 130, 437-460. https://doi.org/10.1016/S1095-6433(01)00442-1 (2001).

66. Tsuge, H., Nakano, Y., Onishi, H., Futamura, Y. \& Ohashi, K. A novel purification and some properties of rat liver mitochondrial choline dehydrogenase. Biochim. Biophys. Acta 614, 274-284 (1980).

67. Schroeder, F. et al. Sterol carrier protein-2: new roles in regulating lipid rafts and signaling. Biochim. Biophys. Acta 1771, 700-718. https://doi.org/10.1016/j.bbalip.2007.04.005 (2007).

68. Lee, A. K., Detweiler, C. S. \& Falkow, S. OmpR regulates the two-component system SsrA-SsrB in Salmonella pathogenicity island 2. J. Bacteriol. 182, 771-781 (2000).

69. Tipton, K. A. \& Rather, P. N. An ompR-env two-component system ortholog regulates phase variation, osmotic tolerance, motility, and virulence in Acinetobacter baumannii strain AB5075. J. Bacteriol. https://doi.org/10.1128/JB.00705-16 (2017).

70. Foo, Y. H., Gao, Y., Zhang, H. \& Kenney, L. J. Cytoplasmic sensing by the inner membrane histidine kinase EnvZ. Prog. Biophys. Mol. Biol. 118, 119-129. https://doi.org/10.1016/j.pbiomolbio.2015.04.005 (2015).

71. Mattison, K. \& Kenney, L. J. Phosphorylation alters the interaction of the response regulator OmpR with its sensor kinase EnvZ. J. Biol. Chem. 277, 11143-11148. https://doi.org/10.1074/jbc.M111128200 (2002).

72. Saenz, J. P. et al. Hopanoids as functional analogues of cholesterol in bacterial membranes. Proc. Natl. Acad. Sci. U. S. A. 112, 11971-11976. https://doi.org/10.1073/pnas.1515607112 (2015).

73. Villalobos Solis, M. I., Giannone, R. J., Hettich, R. L. \& Abraham, P. E. Exploiting the dynamic relationship between peptide separation quality and peptide coisolation in a multiple-peptide matches-per-spectrum approach offers a strategy to optimize bottom-up proteomics throughput and depth. Anal. Chem. 91, 7273-7279. https://doi.org/10.1021/acs.analchem.9b00819 (2019).

74. McIlwain, S. et al. Crux: rapid open source protein tandem mass spectrometry analysis. J. Proteome Res. 13, 4488-4491. https:// doi.org/10.1021/pr500741y (2014).

75. Diament, B. J. \& Noble, W. S. Faster SEQUEST searching for peptide identification from tandem mass spectra. J. Proteome Res. 10, 3871-3879. https://doi.org/10.1021/pr101196n (2011).

76. Kall, L., Canterbury, J. D., Weston, J., Noble, W. S. \& MacCoss, M. J. Semi-supervised learning for peptide identification from shotgun proteomics datasets. Nat. Methods 4, 923-925. https://doi.org/10.1038/nmeth1113 (2007).

77. Argentini, A. et al. moFF: a robust and automated approach to extract peptide ion intensities. Nat. Methods 13, 962-965. https:// doi.org/10.1038/nmeth.4075 (2016).

78. Tyanova, S. et al. The Perseus computational platform for comprehensive analysis of (prote)omics data. Nat. Methods 13, 731-740. https://doi.org/10.1038/nmeth.3901 (2016).

79. Shannon, P. et al. Cytoscape: a software environment for integrated models of biomolecular interaction networks. Genome Res. 13, 2498-2504. https://doi.org/10.1101/gr.1239303 (2003).

80. Bindea, G. et al. ClueGO: a Cytoscape plug-in to decipher functionally grouped gene ontology and pathway annotation networks. Bioinformatics 25, 1091-1093. https://doi.org/10.1093/bioinformatics/btp101 (2009).

81. Holm, S. A simple sequentially rejective multiple test procedure. Scand. J. Stat. 6, 65-70 (1979).

82. Turner, L., Ryu, W. S. \& Berg, H. C. Real-time imaging of fluorescent flagellar filaments. J. Bacteriol. 182, 2793-2801 (2000).

\section{Acknowledgements}

This research was sponsored by the Genomic Science Program, U.S. Department of Energy, Office of Science, Biological and Environmental Research, as part of the Plant Microbe Interfaces Scientific Focus Area (https:// pmi.ornl.gov). Oak Ridge National Laboratory is managed by UT-Battelle LLC, for the U.S. Department of Energy under contract DE-AC05-00OR22725. The United States Government retains and the publisher, by accepting the article for publication, acknowledges that the United States Government retains a non-exclusive, paid-up, irrevocable, world-wide license to publish or reproduce the published form of this manuscript, or allow others to do so, for United States Government purposes. The Department of Energy will provide public access to these results of federally sponsored research in accordance with the DOE Public Access Plan (https://energy.gov/downl oads/doe-public-access-plan). 


\section{Author contributions}

J.M.F., S.V.K., and M.D. designed the experiments. S.V.K. prepared samples for proteomics and transcriptomics and S.V.K. and A.B. performed motility studies. P.A., R.H., G.H., and K.C. performed proteomic experiments and data analyses. S.V.K., A.B., and J.M.F. analyzed and interpreted the data, and S.V.K. and J.M.F. wrote the paper. All authors revised and reviewed the paper.

\section{Competing interests}

The authors declare no competing interests.

\section{Additional information}

Supplementary information is available for this paper at https://doi.org/10.1038/s41598-020-71672-w.

Correspondence and requests for materials should be addressed to J.L.M.-F.

Reprints and permissions information is available at www.nature.com/reprints.

Publisher's note Springer Nature remains neutral with regard to jurisdictional claims in published maps and institutional affiliations.

(c) Open Access This article is licensed under a Creative Commons Attribution 4.0 International License, which permits use, sharing, adaptation, distribution and reproduction in any medium or format, as long as you give appropriate credit to the original author(s) and the source, provide a link to the Creative Commons licence, and indicate if changes were made. The images or other third party material in this article are included in the article's Creative Commons licence, unless indicated otherwise in a credit line to the material. If material is not included in the article's Creative Commons licence and your intended use is not permitted by statutory regulation or exceeds the permitted use, you will need to obtain permission directly from the copyright holder. To view a copy of this licence, visit http://creativecommons.org/licenses/by/4.0/.

This is a U.S. Government work and not under copyright protection in the US; foreign copyright protection may apply 2020 